Research Article

\title{
Effect of Desert Sand on the Mechanical Properties of Desert Sand Concrete (DSC) after Elevated Temperature
}

\author{
Yijiang Liu $(\mathbb{D}$, Weiwu Yang $(\mathbb{D}$, Xiaolong Chen $(\mathbb{D}$, Haifeng Liu $\mathbb{D}$, and Ningna Yan \\ College of Civil and Hydraulic Engineering, Ningxia University, Yinchuan 750021, China \\ Correspondence should be addressed to Haifeng Liu; liuhaifeng1557@163.com
}

Received 11 May 2021; Revised 27 June 2021; Accepted 1 July 2021; Published 10 July 2021

Academic Editor: Shangtong Yang

Copyright (C) 2021 Yijiang Liu et al. This is an open access article distributed under the Creative Commons Attribution License, which permits unrestricted use, distribution, and reproduction in any medium, provided the original work is properly cited.

Building fires and shortage of medium sand resources have become two major issues in building domain. Desert sand was used to produce desert sand concrete (DSC), which was suitable for engineering utility. The mechanical properties tests of DSC with different desert sand replacement ratio (DSRR) were carried out after elevated temperature. The effects of elevated temperature and DSRR on DSC mechanical properties were analyzed. DSC microstructure was investigated by SEM and XRD. Research studies' results showed that the relative compressive strength increased gradually with increasing temperature. The maximum value appeared at $200^{\circ} \mathrm{C}-300^{\circ} \mathrm{C}$, and it began to decrease at $500^{\circ} \mathrm{C}$. Compared with room temperature, the compressive strength at $700^{\circ} \mathrm{C}$ was about $70 \%$ of that at room temperature. Relative splitting tensile strength increased first and then decreased, and the value reached the maximum at $100^{\circ} \mathrm{C}$. DSC relative flexural strength decreased with the temperature. Relative compressive strength, splitting tensile strength, and flexural strength of DSC enhanced first and then decreased with DSRR, and the maximum values were obtained with $40 \%$ DSRR. Based on the regressive analysis, the relative compressive strength was a quadratic polynomial with relative porosity. Relative splitting tensile strength and relative flexural strength were linear with relative porosity. Research results can provide the technical support for DSC engineering application and postfire assessment.

\section{Introduction}

Large-scale engineering construction consumed a large amount of medium sand, which caused the shortage of medium sand resources [1-4]. In Northwest China, there are abundant desert sand resources. If these desert sand resources can be used in engineering practice, it can not only reduce engineering cost but also decrease local desertification pressure and protect local ecological environment.

At present, many scholars had acquired some achievements in desert sand utility. Zhang [5] analyzed the Tengger desert sand chemical and physical properties and conducted the compressive strength test of desert sand mortar and DSC. Seif et al. [6] studied the mechanical performance of dune sand concrete from Kharga Oasis in western Egypt and gave out an optimal mix ratio of dune sand mortar and concrete. Al-Harthy [7] researched DSC mechanical properties. Experimental results showed that DSC slump and mechanical properties decreased with increasing DSRR. Yan
[8] carried out an experiment to study air content, slump, and compressive strength of DSC and gave a method for optimizing DSC mix ratio based on the statistical model. Luo [9] analyzed the effects of sand ratio on DSC compressive strength, elastic modulus, tensile strength, and slump. Liu [10-13] carried out experiment to research the DSC mechanical properties. Zhang $[14,15]$ studied the uniaxial properties of desert sand mortar after elevated temperature.

Construction fires happen frequently and have become one of the most severely damaged disasters $[16,17]$. A lot of research studies had been performed to study the concrete performance after elevated temperature. Annerel [18] gave a method to determine the maximum temperature that a concrete structure can withstand. Ahmad [19] researched the effect of elevated temperature on concrete residual compressive strength and tensile strength. Ferhat [20] analyzed the effect of the cooling method on concrete residual strength after elevated temperature. Jia [21] studied the effect of standing time and the cooling method on concrete 
residual strength after elevated temperature. Lu [22, 23] revealed the changes in mechanical properties, analyzed phase composition, and micromorphology of concrete after elevated temperature by XRD and SEM. Wang [24] analyzed the characteristics of concrete microcrack damage after different temperatures.

There were many research studies that dedicated to concrete mechanical performances after elevated temperature. However, few studies were focused on DSC mechanical properties after elevated temperature. In this study, the DSC compressive strength, splitting tensile strength, and flexural strength tests after elevated temperature were carried out. The effects of elevated temperature and DSRR on DSC mechanical properties were studied. The failure mechanism of DSC after elevated temperature was analyzed, which can provide the technical support for DSC engineering application and postfire assessment.

\section{Materials and Methods}

2.1. Materials. P.O42.5R ordinary Portland cement was adopted, which was branded as Saima, and the performances are listed in Table 1. Local grade-I fly ash was used, and chemical compositions are listed in Table 2. Mu Us desert sand was used, which was obtained from Yanchi County, Ningxia Hui Autonomous Region, and the chemical properties are listed in Table 3. Medium sand was local washed mountain sand. Figure 1 shows the appearance comparison between medium sand and desert sand. Local two-grade artificial crushed stone was used as coarse aggregate. Sizes of large stone and small stone were $10 \sim 20 \mathrm{~mm}$ and $5 \sim 10 \mathrm{~mm}$, and the mass ratio was $7: 3$. The physical performances of desert sand, medium sand, and coarse aggregate are listed in Table 4. Figure 2 shows the raw materials gradation distribution.

2.2. DSC Mixture Proportions. The design standard value of concrete strength was $C 40$, water-binder ratio was 0.45 , sand ratio was 0.32 , and the replacement rate of fly ash was $10 \%$. Water-reducing agent was polycarboxylate superplasticiser, which was used to maintain flow workability of DSC, the water-reducing agent amount was $0.08-0.3 \%$ of the total cementitious material (to ensure the mixture slump about $150 \mathrm{~mm}$ ) and water-reducing rate was above $25 \%$. Desert sand with DSRR of $0 \%, 20 \%, 40 \%, 60 \%, 80 \%$, and $100 \%$ was used to replace medium sand to prepare DSC specimen. DSC mix proportion is given in Table 5 .

Specimens were $100 \mathrm{~mm} \times 100 \mathrm{~mm} \times 400 \mathrm{~mm}$ prisms for the flexural strength test and $100 \mathrm{~mm} \times 100 \mathrm{~mm} \times 100 \mathrm{~mm}$ cubes for the compressive strength and splitting tensile strength test [25]. After the completion of pouring for $24 \mathrm{~h}$, the specimens were taken out from the mold and put into a standard curing room for $28 \mathrm{~d}$ curing.

\subsection{Experiment Methods}

2.3.1. Elevated Temperature Test. Concrete is a thermally inert material. When the temperature reached $700^{\circ} \mathrm{C}$ in a high-temperature furnace, the concrete specimen needed to be kept at setting temperature for $6 \mathrm{~h}$ to make internal and external temperature of the specimen consistent [26]. Yu [27] found that when furnace temperature arrived at setting temperature and kept constant for $3 \mathrm{~h}$, there was no temperature gradient in the cross-section of the concrete specimen.

After being taken out from the standard curing room, the DSC specimen was placed into an oven to dry at $50^{\circ} \mathrm{C}$ for $24 \mathrm{~h}$. Then, an electronic scale with the accuracy of $0.01 \mathrm{~g}$ and the range of $10 \mathrm{~kg}$ was used to weigh specimen mass. A hightemperature furnace (CSL-26-17) was used for the elevated temperature test with the setting temperatures of $100^{\circ} \mathrm{C}$, $300^{\circ} \mathrm{C}, 500^{\circ} \mathrm{C}, 700^{\circ} \mathrm{C}$, and $900^{\circ} \mathrm{C}$. After reaching the setting temperature, the temperature in the high-temperature furnace was kept constant for $4 \mathrm{~h}$ to ensure the internal and external temperature of specimen were consistent. Finally, the concrete specimen was taken out from the high-temperature furnace. Figure 3 shows the DSC temperaturerising curve, and specimen mass was weighed again after natural cooling. Mass loss rate was used to evaluate specimen mass change $[28,29]$, and the formula is given as follows.

$$
\omega(s, T)=\frac{m(s, 20)-m(s, T)}{m(s, 20)} \times 100 \%,
$$

where $\omega(s, T)$ represents the DSC mass loss rate (\%); $m(s$, 20) represents the DSC specimen mass at room temperature, $\mathrm{kg} ; m(s, T)$ represents the DSC specimen mass after elevated temperature, kg; $s$ represents the DSRR (\%); Trepresents the elevated temperature, ${ }^{\circ} \mathrm{C}$.

2.3.2. Ultrasonic Wave Velocity Test. An NM-4A nonmetallic ultrasonic analyzer was used to test ultrasonic wave velocity of the DSC specimen. After the elevated temperature test, the DSC ultrasonic wave velocity can be measured when the specimens were allowed to stand in the room for 7 days. The ultrasonic wave velocity test is shown in Figure 4. Five measurement points were selected on opposite sides, and the specific locations of measurement points are shown in Figure 5. To couple concrete specimen with an ultrasonic probe, a small amount of petroleum jelly was evenly applied to both probes and measurement points. Ultrasonic wave velocity at each measurement point was measured three times. The average value of five measurement points was taken as DSC ultrasonic wave velocity.

2.3.3. Mechanical Properties Test. After finishing the ultrasonic wave velocity test, a universal testing machine (CMT5305) was used to test DSC mechanical properties. Loading rates of compressive strength, splitting tensile strength, and flexural strength tests were $0.5 \mathrm{MPa} / \mathrm{s}$, $0.05 \mathrm{MPa} / \mathrm{s}$, and $0.05 \mathrm{MPa} / \mathrm{s}$, respectively [25]. The loading diagram is shown in Figure 6.

DSC compressive strength was calculated by following equation [25]: 
TABLE 1: Cement performance.

\begin{tabular}{|c|c|c|c|c|c|c|c|c|c|c|c|}
\hline \multirow[t]{2}{*}{$\begin{array}{l}\text { Fineness } \\
(\%)\end{array}$} & \multirow[t]{2}{*}{ SCWC (\%) } & \multirow[t]{2}{*}{ Stability } & \multicolumn{2}{|c|}{$\begin{array}{l}\text { Setting time } \\
\quad(\min )\end{array}$} & \multicolumn{2}{|c|}{$\begin{array}{c}\text { Flexural } \\
\text { strength } \\
(\mathrm{MPa})\end{array}$} & \multicolumn{2}{|c|}{$\begin{array}{c}\text { Compressive } \\
\text { strength } \\
(\mathrm{MPa})\end{array}$} & \multirow[t]{2}{*}{ LOI (\%) } & \multirow[t]{2}{*}{$\mathrm{MgO}(\%)$} & \multirow[t]{2}{*}{$\mathrm{SO}_{3}(\%)$} \\
\hline & & & Initial & Final & $3 \mathrm{~d}$ & $28 \mathrm{~d}$ & $3 \mathrm{~d}$ & $28 \mathrm{~d}$ & & & \\
\hline 4.7 & 27.2 & Aptitude & 182 & 234 & 6.6 & 8.7 & 33.4 & 54.8 & 4.7 & 2.04 & 2.93 \\
\hline
\end{tabular}

SCWC, standard consistency water consumption; LOI, loss on ignition.

TABLE 2: Fly ash chemical composition.

\begin{tabular}{|c|c|c|c|c|c|c|c|c|c|c|c|}
\hline $\begin{array}{l}\mathrm{SiO}_{2} \\
(\%) \\
\end{array}$ & $\begin{array}{c}\mathrm{Al}_{2} \mathrm{O}_{3} \\
(\%)\end{array}$ & $\begin{array}{c}\mathrm{CaO} \\
(\%) \\
\end{array}$ & $\begin{array}{c}\mathrm{Fe}_{2} \mathrm{O}_{3} \\
(\%)\end{array}$ & $\begin{array}{c}\mathrm{MgO} \\
(\%)\end{array}$ & $\begin{array}{l}\mathrm{SO}_{3} \\
(\%) \\
\end{array}$ & $\begin{array}{c}\mathrm{P}_{2} \mathrm{O}_{5} \\
(\%) \\
\end{array}$ & $\begin{array}{c}\mathrm{Na}_{2} \mathrm{O} \\
(\%)\end{array}$ & $\begin{array}{l}\mathrm{K}_{2} \mathrm{O} \\
(\%) \\
\end{array}$ & $\begin{array}{c}\text { Fineness }(45 \mu \mathrm{m} \text { sieve } \\
\text { residue }) / \%\end{array}$ & $\begin{array}{l}\text { Specific surface } \\
\text { area }\left(\mathrm{m}^{2} \cdot \mathrm{g}^{-1}\right)\end{array}$ & $\begin{array}{l}\text { LOI } \\
(\%)\end{array}$ \\
\hline 41.5 & 24.8 & 5.68 & 7.01 & 3.49 & 2.45 & 1.23 & 11.7 & 2.14 & 5.1 & 0.51 & 1.83 \\
\hline
\end{tabular}

TABLe 3: Fine aggregate chemical composition.

\begin{tabular}{lcccccccc}
\hline Fine aggregate & $\mathrm{SiO}_{2}(\%)$ & $\mathrm{Al}_{2} \mathrm{O}_{3}(\%)$ & $\mathrm{CaO}(\%)$ & $\mathrm{FeO}(\%)$ & $\mathrm{MgO}(\%)$ & $\mathrm{Na}_{2} \mathrm{O}(\%)$ & $\mathrm{K}_{2} \mathrm{O}(\%)$ & $\mathrm{LOI}(\%)$ \\
\hline Desert sand & 82.66 & 8.72 & 2.00 & 1.85 & 1.51 & 0.07 & 0.12 & 2.9 \\
Medium sand & 86.55 & 9.74 & 0.96 & 0.98 & 1.09 & - & - & - \\
\hline
\end{tabular}

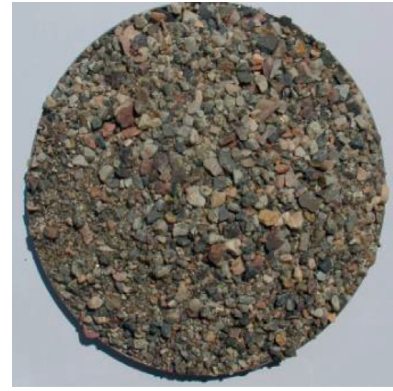

(a)

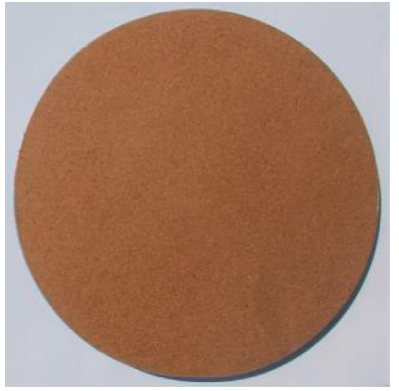

(b)

Figure 1: Appearance comparison between medium sand and desert sand. (a) Medium sand. (b) Desert sand.

TABle 4: Physical properties of aggregates.

\begin{tabular}{lccccccc}
\hline Aggregate & $\begin{array}{c}\text { Fineness } \\
\text { modulus }\end{array}$ & $\begin{array}{c}\text { Bulk density } \\
\left(\mathrm{kg} \cdot \mathrm{m}^{-3}\right)\end{array}$ & $\begin{array}{c}\text { Apparent density } \\
\left(\mathrm{kg} \cdot \mathrm{m}^{-3}\right)\end{array}$ & $\begin{array}{c}\text { Specific surface area } \\
\left(\mathrm{m}^{2} \cdot \mathrm{g}^{-1}\right)\end{array}$ & $\begin{array}{c}\text { Specific } \\
\text { gravity }\end{array}$ & $\begin{array}{c}\text { Mud content } \\
(\%)\end{array}$ & $\begin{array}{c}\text { Crushing index } \\
(\%)\end{array}$ \\
\hline $\begin{array}{l}\text { Desert sand } \\
\text { Medium sand }\end{array}$ & 0.24 & 1400 & 2624 & 0.14 & 2.62 & 0.14 & - \\
Coarse & 3.43 & 1545 & 2543 & - & 2.67 & 0.72 & - \\
aggregate & - & 1430 & 2698 & - & 2.73 & 0.78 & 8.6 \\
\hline
\end{tabular}

$$
f_{c}(s, T)=\frac{F_{c}}{A_{c}}
$$

where $f_{c}(s, T)$ represents the DSC compressive strength after elevated temperatures, $\mathrm{MPa} ; F_{c}$ represents the failure load under uniaxial compression, $\mathrm{N}$; $A_{c}$ represents the bearing area, $\mathrm{mm}^{2}$.

DSC splitting tensile strength was expressed by the following equation [25]:

$$
f_{t}(s, T)=\frac{F_{t}}{A},
$$

where $f_{t}(s, T)$ represents the DSC splitting tensile strength after elevated temperatures, $\mathrm{MPa} ; F_{t}$ represents the failure load in splitting tension, $\mathrm{N}$; $A$ represents the specimen splitting surface area, $\mathrm{mm}^{2}$.

DSC flexural strength was calculated by the following equation [25]: 


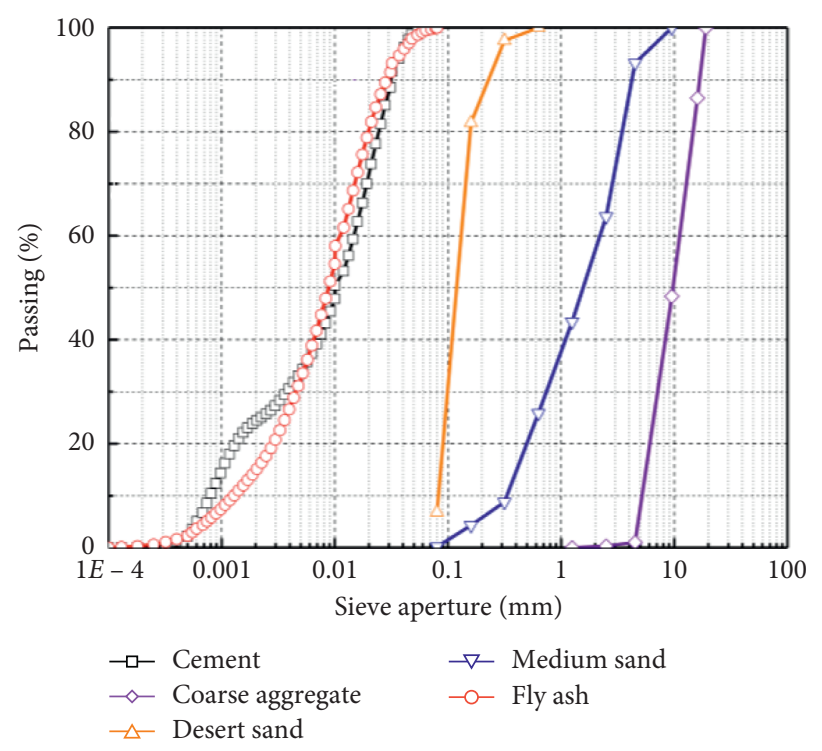

FIGURE 2: Gradation distribution of raw materials.

TABLE 5: Mix proportion of DSC.

\begin{tabular}{lccccccccc}
\hline & & \multicolumn{7}{c}{ Material consumption unit volume $\left(\mathrm{kg} \cdot \mathrm{m}-{ }^{3}\right)$} \\
No. & DSRR (\%) & Water & Cement & Fly ash & \multicolumn{2}{c}{ Fine aggregate } & \multicolumn{2}{c}{ Coarse aggregate } & Water-reducing agent (\%) \\
& & & & & & Medium sand & Desert sand & 10 20 mm & $5 \sim 10 \mathrm{~mm}$ \\
\hline DSRR-0\% & 0 & 190 & 380 & 46 & 572 & 0 & 851 & 365 & 0.08 \\
DSRR-20\% & 20 & 190 & 380 & 46 & 458 & 114 & 851 & 365 & 0.10 \\
DSRR-40\% & 40 & 190 & 380 & 46 & 343 & 229 & 851 & 365 & 0.13 \\
DSRR-60\% & 60 & 190 & 380 & 46 & 229 & 343 & 851 & 365 & 0.16 \\
DSRR-80\% & 80 & 190 & 380 & 46 & 114 & 458 & 851 & 365 & 0.25 \\
DSRR-100\% & 100 & 190 & 380 & 46 & 0 & 572 & 851 & 365 & 0.30 \\
\hline
\end{tabular}

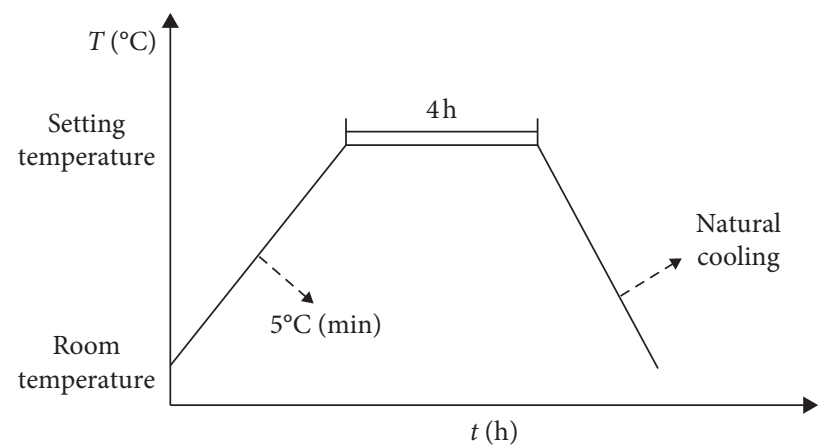

Figure 3: Temperature-rising curve.

$$
f_{f}(s, T)=\frac{F l}{b h^{2}},
$$

where $f_{f}(s, T)$ represents the DSC flexural strength after elevated temperatures, $\mathrm{MPa} ; F$ represents the flexural failure load, $\mathrm{N} ; l$ represents the span of two supports, $\mathrm{mm} ; h$ represents the specimen height, $\mathrm{mm} ; b$ represents the specimen width, mm.
2.3.4. Neutralization Test. The neutralization test was performed on the concrete specimen after splitting tensile strength experiment. Measurement points with an equal interval of $10 \mathrm{~mm}$ on each side were selected [30]. Then, $100 \%$ pure ethanol was diluted to $80 \%$ ethanol solution, and $1 \%$ phenol phthalate was added to prepare a mixed solvent. The mixed solvent was sprayed on the DSC specimen cutting section. After $30 \mathrm{~s}$, an electronic vernier caliper with an 


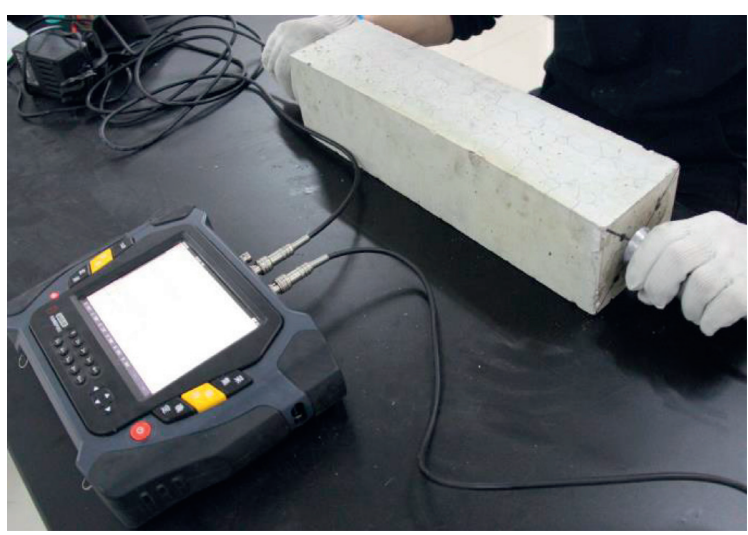

FIGURE 4: Ultrasonic wave velocity test of DSC.

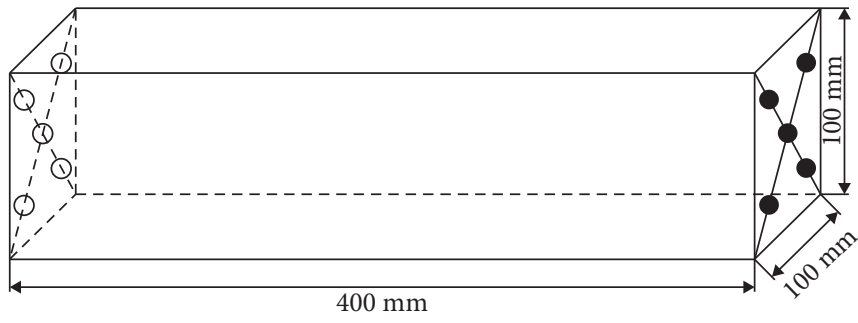

(a)

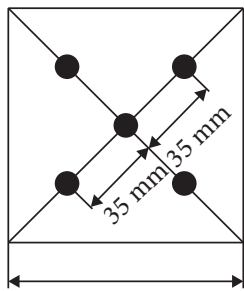

$100 \mathrm{~mm}$

(b)

Figure 5: Measurement points used in the ultrasonic wave velocity test. (a) Layout of measurement points. (b) Front view of measurement points.

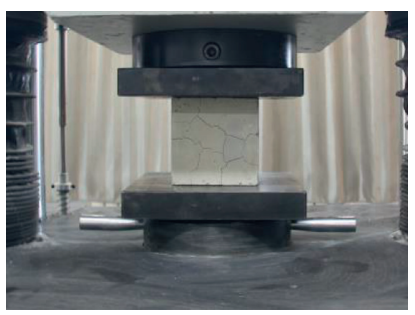

(a)

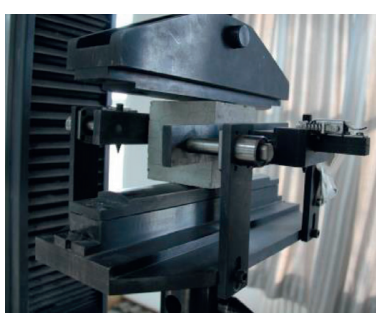

(b)

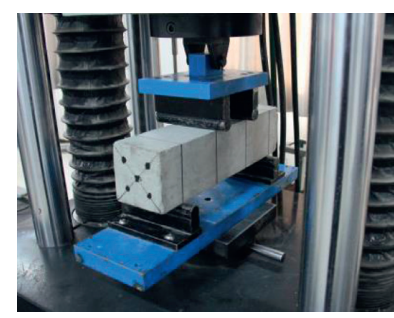

(c)

Figure 6: Loading diagram of DSC. (a) Uniaxial compressive test. (b) Splitting tensile strength test. (c) Flexural strength test.

accuracy of $0.001 \mathrm{~mm}$ was used to measure neutralization depth. The average neutralization depth was calculated by the following equation.

$$
\bar{d}(s, T)=\frac{1}{n} \sum_{i=1}^{n} d_{i},
$$

where $\bar{d}(s, T)$ represents the average neutralization depth of DSC, $\mathrm{mm}$; $d_{i}$ represents the neutralization depth at each measuring point, $\mathrm{mm} ; n$ represents the measuring points.

2.3.5. Pore Structure Analysis. After the flexural strength test, the DSC specimen was cut into $2 \mathrm{~cm}$ slices by a cutter [31]. A digital camera was used to observe DSC internal changes after elevated temperature. Each cut surface was polished with sandpaper of 400, 2000, and 5000 mesh for more than 20 minutes to make the surface smooth and flat. The surface blackened with ink needed to be air-dried, and the holes on the surface needed to be filled with fine nanometer $\mathrm{CaCO}_{3}$ powder, and then, the excess powder attached to the surface was removed, so as to obtain an observation surface with obvious black and white contrast.

On the basis of the stereology method [32], an optical stereo microscope was used to amplify DSC slice by 50 times to obtain an RGB picture with a resolution of $640 \times 480$. Then, the RGB pictures were used to analyze pore structure of DSC by means of ImagePro Plus software.

2.3.6. X-Ray Analysis (XRD). XRD was performed by an X-ray powder diffractometer (D/MARX2200/PC) manufactured by Japanese Rigaku Company, and the scanning range was $3^{\circ}-85^{\circ}$. The sample to be subjected to the XRD test 
was taken out from the broken part after the compressive strength test, the sample was placed in a mortar for grinding, and the particle size was less than $10 \mu \mathrm{m}$. Then, the sample was filled into a special plexiglass concave grid and was compacted and smoothed. After being dropped a few drops of alcohol, the prepared sample was placed on the X-ray diffract meter for scanning.

2.3.7. Scanning Electron Microscopy (SEM). A KYKY-2800B electron microscope was used for the SEM test. The resolution was $40 \sim 50 \AA$, and magnification times were 1.5 250000x. Samples were several flakes and selected from the core and surface of the crushed DSC specimen after the compressive strength test. After being dust-removed by a laboratory-specific balloon, air-dried, vacuum-treated, and vacuum-sprayed with a carbon film with a thickness of $300 \AA$, the flakes were applied to SEM.

\section{Experimental Results and Analysis}

The mass loss rate, compressive strength, splitting tensile strength, flexural strength, ultrasonic wave velocity, and neutralization depth of DSC with different DSRRs after different temperatures are given in Table 6 . The data in the subsequent analysis of the results were all derived from this table.

3.1. Apparent Characteristics. Figures 7 and 8 show the typical surface pictures of DSRR- $0 \%$ and DSRR- $60 \%$ specimens after elevated temperatures. The DSC specimen surface color changed from dark grey, yellowing and to whitening with increasing temperature. The DSC specimens surface cracks were nucleated and stretched simultaneously $[33,34]$. After $700^{\circ} \mathrm{C}$, the DSC specimen surface had been peeled, and coarse aggregates had been leaked out. After $900^{\circ} \mathrm{C}$, some DSC specimens became so loose that mechanical properties, neutralization depth, and the ultrasonic wave velocity test could not be performed.

Surface cracks of the DSRR-0\% specimen occurred after $300^{\circ} \mathrm{C}$. Whereas, the surface cracks of the DSRR- $60 \%$ specimen appeared after $500^{\circ} \mathrm{C}$. The surface cracks of the DSRR- $0 \%$ specimen subjected to $500^{\circ} \mathrm{C}, 700^{\circ} \mathrm{C}$, and $900^{\circ} \mathrm{C}$ were wider than those of DSRR- $60 \%$. The number of surface cracks of the DSRR- $0 \%$ specimen subjected to $500^{\circ} \mathrm{C}, 700^{\circ} \mathrm{C}$, and $900^{\circ} \mathrm{C}$ was more than that of DSRR- $60 \%$. After $900^{\circ} \mathrm{C}$, the peeling part of the DSRR-0\% specimen was larger than that of DSRR- $60 \%$.

3.2. Mass Loss Rate. Figure 9 shows that the DSC mass loss rate enhanced with increasing temperature, which increased quickly from room temperature to $300^{\circ} \mathrm{C}$, enhanced slowly with the range from $300^{\circ} \mathrm{C}$ to $500^{\circ} \mathrm{C}$, and rose fast from $500^{\circ} \mathrm{C}$ to $700^{\circ} \mathrm{C}$. This may be caused by moisture evaporation, dehydration of C-S-H gel, and chemical decomposition of $\mathrm{CH}$ and $\mathrm{CaCO}_{3}$ [34-36]. Figure 10 shows that the DSC relative mass loss rate enhanced first and then decreased with increasing DSRR. When DSRR was $20 \%$, the mass loss rate reached the maximum value.
On the basis of regression analysis on experimental results, the relation between mass loss rate, temperature, and DSRR was established. The coefficient of correlation $R^{2}$ was 0.977, which showed that the relation was effective to predict DSC mass loss after elevated temperature.

$$
\begin{aligned}
\frac{\omega(s, T)}{\omega}= & 1.48173-0.27603\left(\frac{T-20}{700}\right)^{2} \\
& +9.63861 s+0.00534\left(\frac{T-20}{700}\right),
\end{aligned}
$$

where $\omega$ represents the mass loss rate of ordinary concrete after elevated temperature (\%).

\subsection{Relative Strength of DSC}

3.3.1. Relative Compressive Strength. DSC relative compressive strength increased first and then decreased with the increase of temperature, which was about 0.65 after $700^{\circ} \mathrm{C}$ (Figure 11). From room temperature to $300^{\circ} \mathrm{C}$, the DSC internal structure was compact. Temperature made free water in the DSC specimen evaporate, and unhydrated cement particles continue to hydrate, which improved the cement matrix strength. Moreover, the secondary reaction of hydration was continued as elevated temperature increased [32, 36-38]. So, the DSC compressive strength increased. From $300^{\circ} \mathrm{C}$ to $500^{\circ} \mathrm{C}$, C-S-H gel and $\mathrm{CH}$ were dehydrated and decomposed gradually. Many new microcracks were nucleated and stretched, which were caused by temperature stress due to the rapid heating. The inner structure was seriously damaged, and the compressive strength of DSC decreased [23]. At $700^{\circ} \mathrm{C}, \mathrm{C}-\mathrm{S}-\mathrm{H}$ gel and $\mathrm{CH}$ crystals were decomposed completely. The whole structure became looser, which led to the decline in DSC strength [22, 23].

As shown in Figure 12, the DSC relative compressive strength enhanced first and then decreased with increasing DSRR after elevated temperature, and the maximum value was obtained when DSRR was $40 \%$. Desert sand was ultrafine sand [5], and the particle was smaller than that of ordinary medium sand. When DSRR was less than $40 \%$, with the increment of DSRR, desert sand can effectively fill the gaps between cement mortar and coarse aggregate. DSC became more compacted, which can increase the DSC strength $[9,11,39]$. When DSRR was $40 \%$, the aggregate gradation curve was optimal, so that DSC relative compressive strength can arrive at the maximum value. When DSRR was more than $40 \%$, the specific surface area of fine aggregate increased. More grouts were needed to attach around fine aggregate, which caused the decrease in compressive strength $[7,11,12]$. Moreover, desert sand was formed by the weathering of loose rock, and the strength was lower than that of ordinary medium sand [11, 13-16]. Therefore, the DSC relative compressive strength after elevated temperature decreased with increasing DSRR.

On the basis of the compressive strength experimental results, the regression model between relative compressive strength, temperature, and DSRR was formulated. The correlation coefficient $\left(R^{2}\right)$ was 0.9605 , which indicated that 
TABLE 6: Experimental results of DSC after elevated temperature.

\begin{tabular}{|c|c|c|c|c|c|c|c|}
\hline Index & $T\left({ }^{\circ} \mathrm{C}\right)$ & DSRR-0\% & DSRR-20\% & DSRR- $40 \%$ & DSRR-60\% & DSRR- $80 \%$ & DSRR-100\% \\
\hline \multirow{5}{*}{ Mass loss rate (\%) } & RT & 0 & 0 & 0 & 0 & 0 & 0 \\
\hline & 100 & 0.64 & 0.73 & 0.68 & 0.65 & 0.63 & 0.62 \\
\hline & 300 & 3.10 & 3.50 & 3.35 & 3.16 & 3.08 & 3.03 \\
\hline & 500 & 4.31 & 4.80 & 4.77 & 4.30 & 3.96 & 3.88 \\
\hline & 700 & 6.48 & 6.86 & 6.63 & 6.30 & 5.96 & 5.72 \\
\hline \multirow{5}{*}{ Compressive strength (MPa) } & RT & 47.67 & 48.79 & 51.09 & 48.29 & 46.85 & 43.67 \\
\hline & 100 & 50.82 & 51.62 & 56.24 & 53.54 & 48.57 & 47.07 \\
\hline & 300 & 48.50 & 50.77 & 56.31 & 54.94 & 51.02 & 47.37 \\
\hline & 500 & 42.26 & 47.58 & 49.65 & 44.38 & 42.05 & 40.79 \\
\hline & 700 & 34.06 & 34.55 & 35.20 & 31.50 & 30.84 & 30.00 \\
\hline \multirow{5}{*}{ Splitting tensile strength $(\mathrm{MPa})$} & RT & 1.88 & 1.94 & 2.40 & 1.99 & 1.76 & 1.75 \\
\hline & 100 & 1.99 & 2.04 & 2.45 & 2.12 & 1.77 & 1.80 \\
\hline & 300 & 1.14 & 1.20 & 1.59 & 1.35 & 1.23 & 1.36 \\
\hline & 500 & 0.81 & 0.84 & 0.91 & 0.89 & 0.78 & 0.75 \\
\hline & 700 & 0.66 & 0.68 & 0.74 & 0.61 & 0.65 & 0.54 \\
\hline \multirow{5}{*}{ Flexural strength $(\mathrm{MPa})$} & RT & 3.45 & 3.53 & 3.89 & 3.63 & 3.45 & 3.43 \\
\hline & 100 & 3.07 & 3.36 & 3.59 & 3.45 & 3.27 & 3.25 \\
\hline & 300 & 2.26 & 2.45 & 2.64 & 2.31 & 2.33 & 2.30 \\
\hline & 500 & 1.04 & 1.34 & 1.36 & 1.31 & 1.20 & 1.16 \\
\hline & 700 & 0.73 & 0.95 & 0.99 & 0.98 & 0.97 & 0.94 \\
\hline \multirow{5}{*}{ Ultrasonic wave velocity $\left(\mathrm{km} \cdot \mathrm{s}^{-1}\right)$} & RT & 4.28 & 4.37 & 4.41 & 4.32 & 4.25 & 4.16 \\
\hline & 100 & 4.22 & 4.33 & 4.37 & 4.28 & 4.23 & 4.18 \\
\hline & 300 & 3.55 & 3.77 & 3.74 & 3.71 & 3.68 & 3.66 \\
\hline & 500 & 1.51 & 1.79 & 1.81 & 1.83 & 1.81 & 1.91 \\
\hline & 700 & 1.21 & 1.37 & 1.46 & 1.66 & 1.60 & 1.74 \\
\hline \multirow{4}{*}{ Neutralization depth (mm) } & RT & 1.88 & 1.84 & 1.62 & 1.50 & 1.50 & 1.51 \\
\hline & 100 & 1.87 & 1.79 & 1.58 & 1.55 & 1.21 & 1.14 \\
\hline & 300 & 1.93 & 1.98 & 1.73 & 1.63 & 1.40 & 1.38 \\
\hline & 500 & 5.81 & 5.15 & 5.55 & 4.81 & 4.56 & 3.81 \\
\hline
\end{tabular}

$\mathrm{RT}$, room temperature.

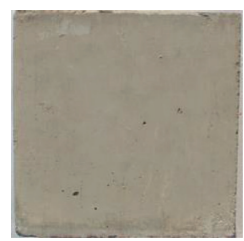

(a)

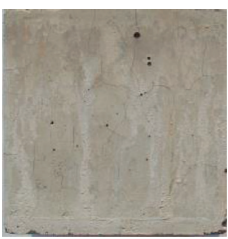

(b)

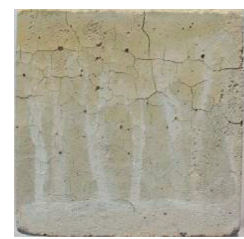

(c)

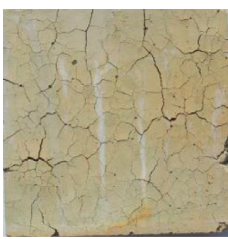

(d)

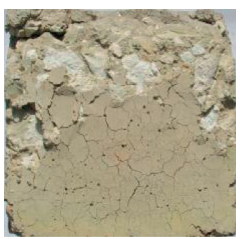

(e)

Figure 7: Typical pictures of the DSRR-0\% specimen after elevated temperature. (a) $100^{\circ} \mathrm{C}$. (b) $300^{\circ} \mathrm{C}$. (c) $500^{\circ} \mathrm{C}$. (d) $700^{\circ} \mathrm{C}$. (e) $900^{\circ} \mathrm{C}$.

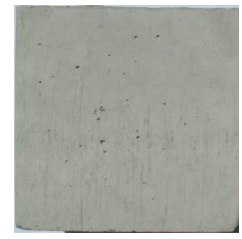

(a)

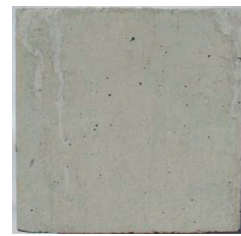

(b)

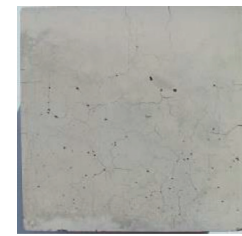

(c)

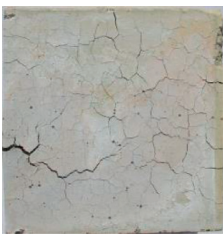

(d)

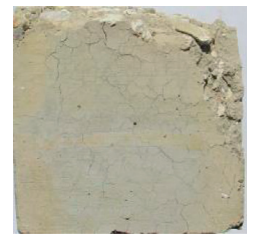

(e)

Figure 8: Typical pictures of the DSRR-60\% specimen after elevated temperature. (a) $100^{\circ} \mathrm{C}$. (b) $300^{\circ} \mathrm{C}$. (c) $500^{\circ} \mathrm{C}$. (d) $700^{\circ} \mathrm{C}$. (e) $900^{\circ} \mathrm{C}$. 


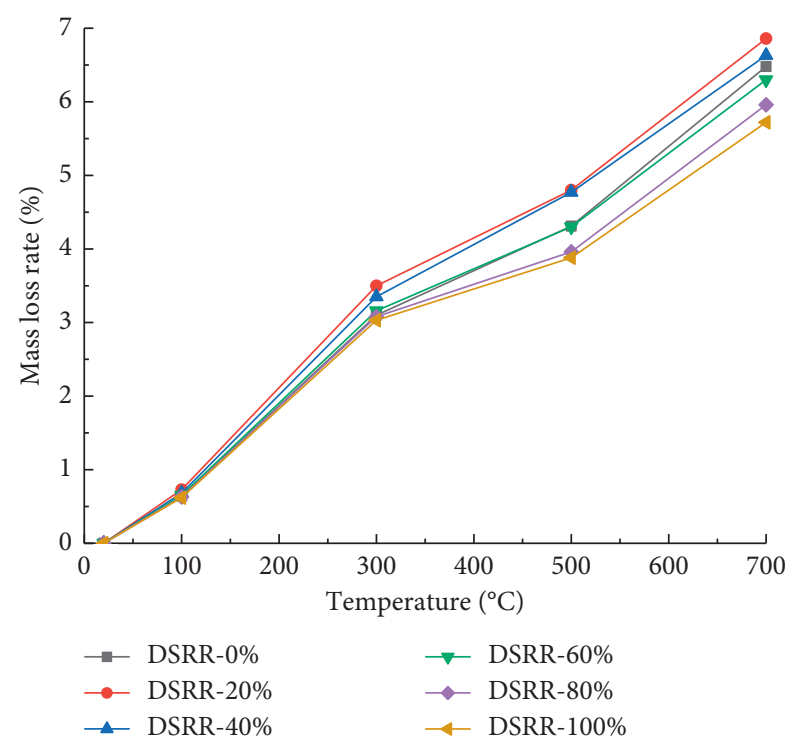

Figure 9: Relation between mass loss rate and temperature.

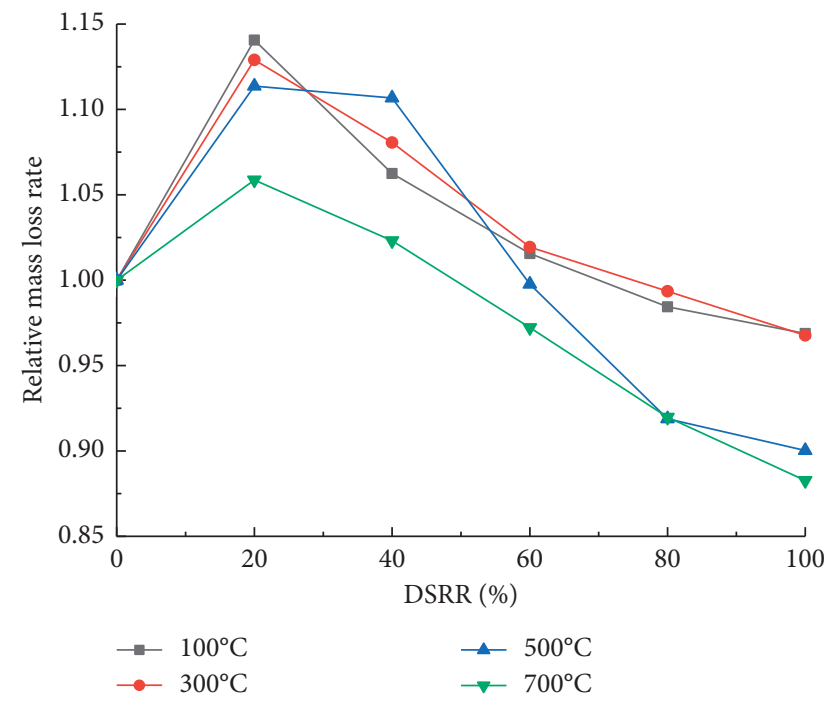

FIGURE 10: Relation between relative mass loss rate and DSRR.

the relation was effective to predict DSC compressive strength after different temperatures.

$$
\begin{aligned}
\frac{f_{c}(s, T)}{f_{c}}= & 1.0012-0.07581\left(\frac{T-20}{700}\right)^{2} \\
& +0.49251 s+0.08005\left(\frac{T-20}{700}\right)-0.86187 s^{2},
\end{aligned}
$$

where $f_{\mathrm{c}}$ represents the compressive strength of ordinary concrete at room temperature, MPa.

3.3.2. Relative Splitting Tensile Strength. Figure 13 shows that the relative splitting tensile strength of DSC rose first and then dropped, which reached the peak value when the temperature was $100^{\circ} \mathrm{C}$. The DSC relative splitting tensile strength enhanced first and then decreased with DSRR

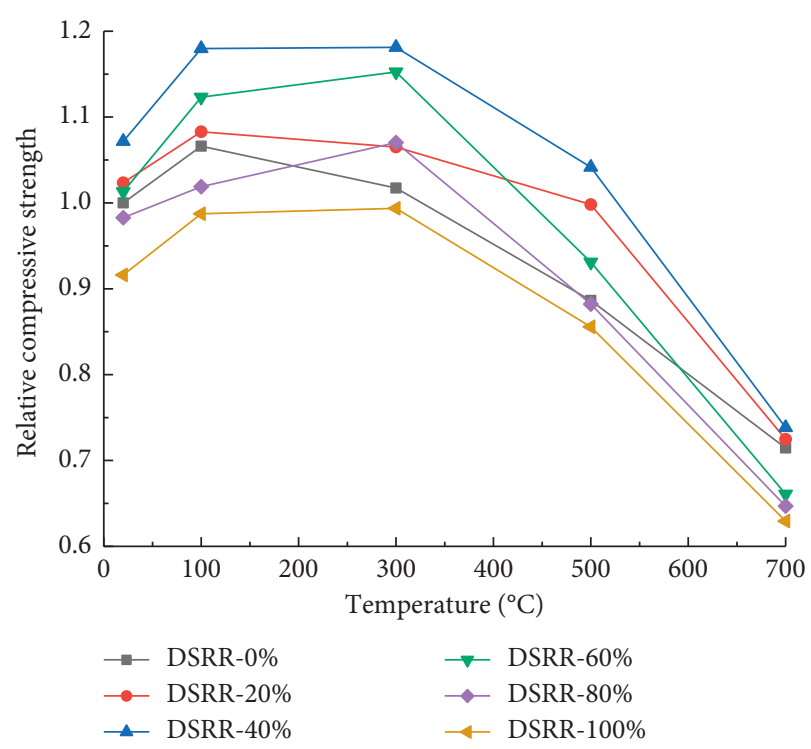

FIGURE 11: Relation between relative compressive strength and temperature.

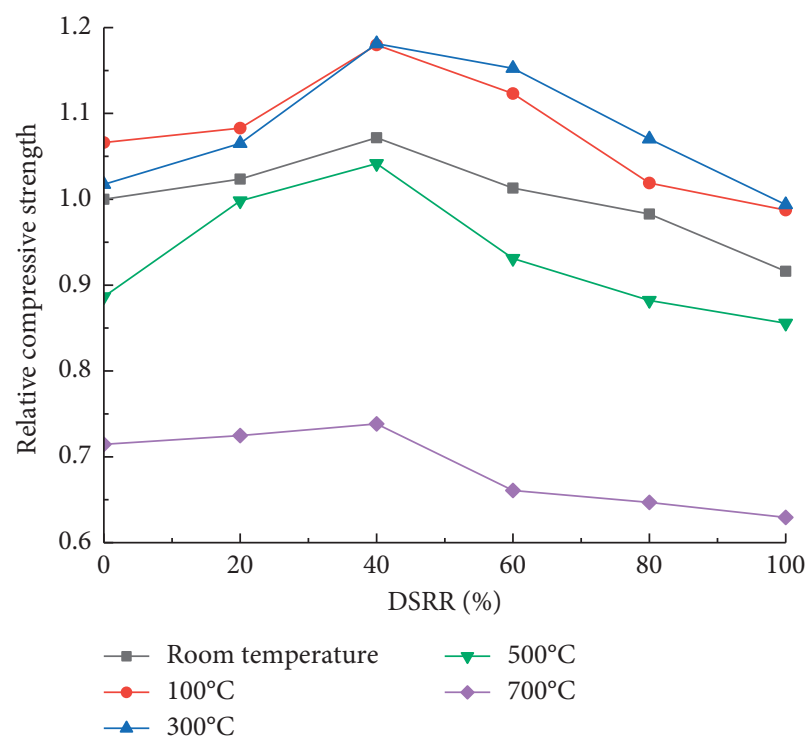

Figure 12: Relation between relative compressive strength and DSRR.

(Figure 14). When DSRR was 40\%, DSC relative splitting tensile strength reached the maximum value. Related research [40] demonstrated that the DSC splitting tensile strength increased first and then decreased with the enhancement of temperature, and the splitting tensile strength at $100^{\circ} \mathrm{C}$ was the largest, which was consistent with the law of this article.

The regression relation between relative splitting tensile strength, temperature, and DSRR was formulated based on the splitting tensile strength experimental results. The correlation coefficient $\left(R^{2}\right)$ was 0.9405 , which was effective to predict DSC splitting tensile strength after elevated temperature. 


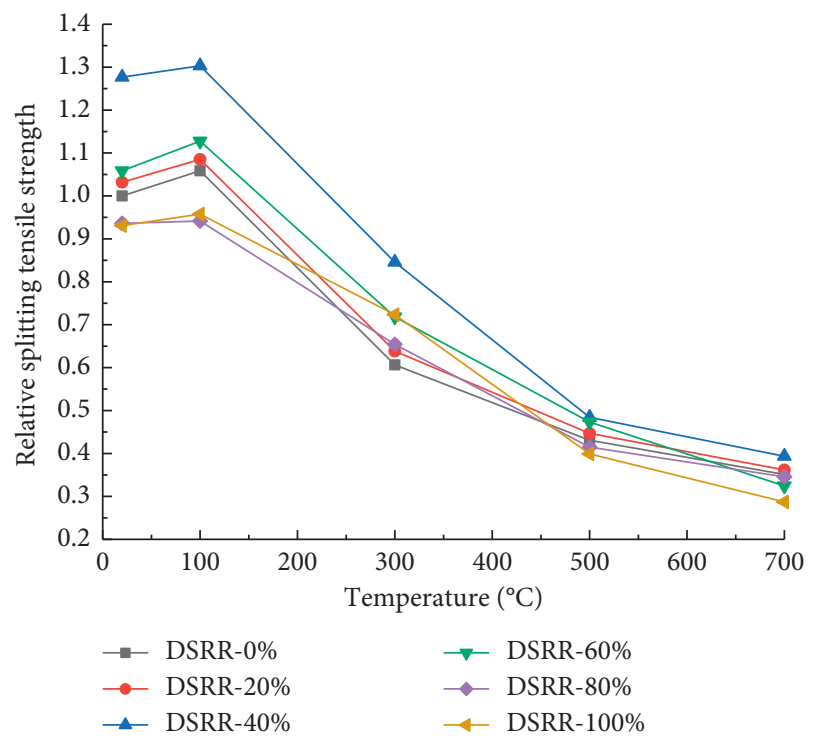

FIGURE 13: Relation between relative splitting tensile strength and temperature.

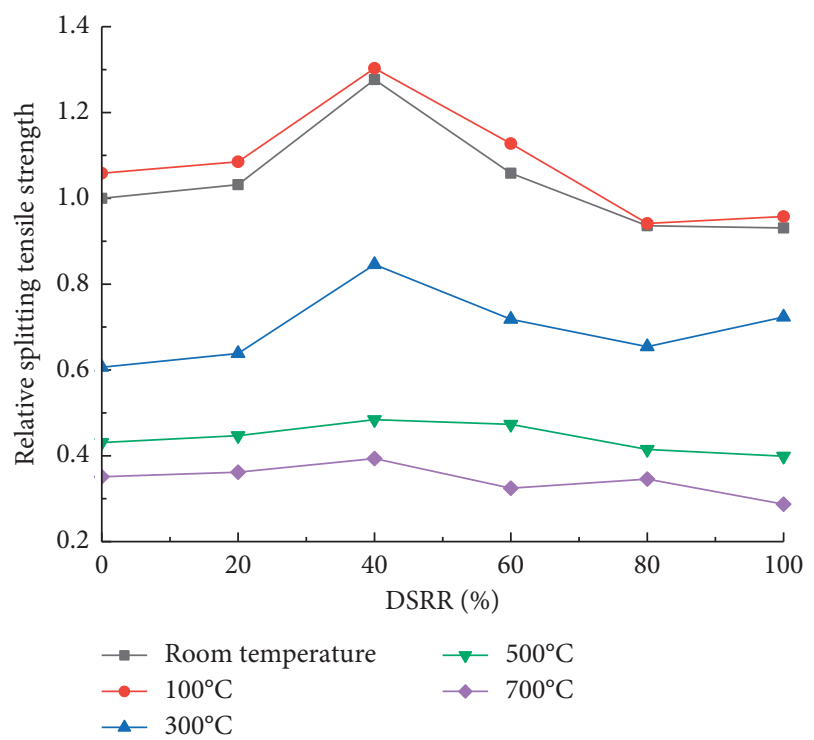

FIGURE 14: Relation between relative splitting tensile strength and DSRR.

$$
\begin{aligned}
\frac{f_{t}(s, T)}{f_{t}}= & 1.02867+0.04503\left(\frac{T-20}{700}\right)^{2}-0.78236 s \\
& -0.02226\left(\frac{T-20}{700}\right)
\end{aligned}
$$

where $f_{t}$ represents the splitting tensile strength of ordinary concrete at room temperature, $\mathrm{MPa}$.

3.3.3. Relative Flexural Strength. Different from relative splitting tensile strength and compressive strength, DSC relative flexural strength declined with increasing temperature (Figure 15). When the temperature was $700^{\circ} \mathrm{C}$, DSC relative flexural strength was below 0.3 , which was less than the relative splitting tensile strength and compressive strength.

On the whole, DSC relative flexural strength enhanced first and then declined with increasing DSRR. When DSRR was $40 \%$, DSC relative flexural strength arrived at the maximum value (Figure 16). Related research [12] revealed that the dynamic flexural strength of DSC after high temperature increased first and then decreased with increasing DSRR. The DSC flexural strength of DSRR-40\% was also the largest.

By means of regression analysis on the flexural strength experimental results, the relation between relative flexural strength, temperature, and DSRR was deduced. The correlation coefficient $\left(R^{2}\right)$ was 0.9693 , which can be used to predict DSC flexural strength after elevated temperature.

$$
\begin{aligned}
\frac{f_{f}(s, T)}{f_{f}}= & 0.97901-0.07129\left(\frac{T-20}{700}\right)^{2} \\
& -0.82257 s+0.09262\left(\frac{T-20}{700}\right),
\end{aligned}
$$

where $f_{f}$ represents the splitting tensile strength of ordinary concrete at room temperature, $\mathrm{MPa}$.

3.4. Relative Ultrasonic Wave Velocity. As shown in Figure 17, relative ultrasonic wave velocity decreased gradually with increasing temperature. The ultrasonic wave velocity was related to porosity and moisture content in the DSC specimen. With the enhancement of elevated temperature, more microcracks were nucleated, stretched, and interacted with each other. Due to a series of physical and chemical reaction, more pores were nucleated. The whole internal structure became looser. When encountered these defects, the ultrasonic wave would diffract along the edge of these defects, and ultrasonic wave velocity was decreased [41]. At $100^{\circ} \mathrm{C}$, the vaporization of free water and bound water led to pore's formation. From $300^{\circ} \mathrm{C}$ to $500^{\circ} \mathrm{C}$, the cement hydrate began to be dehydrated and decomposed, which resulted in a large number of pores and cracks [23]. Therefore, when the temperature was less than $500^{\circ} \mathrm{C}$, the ultrasonic velocity dropped faster.

Figure 18 shows that the relationship between relative ultrasonic wave velocity and DSRR after elevated temperature. When temperature was less than $300^{\circ} \mathrm{C}$, DSC relative ultrasonic wave velocity increased first and then decreased with increasing DSRR, and the maximum value was reached with $20 \%$ DSRR. However, the relative ultrasonic wave velocity in the DSC specimen after $500^{\circ} \mathrm{C}$ and $700^{\circ} \mathrm{C}$ increased with increasing DSRR.

On the basis of experimental results, the relation between ultrasonic wave velocity, temperature, and DSRR was formulated. The correlation coefficient $\left(R^{2}\right)$ was 0.9203 , which can be used to predict DSC ultrasonic wave velocity after elevated temperature. 


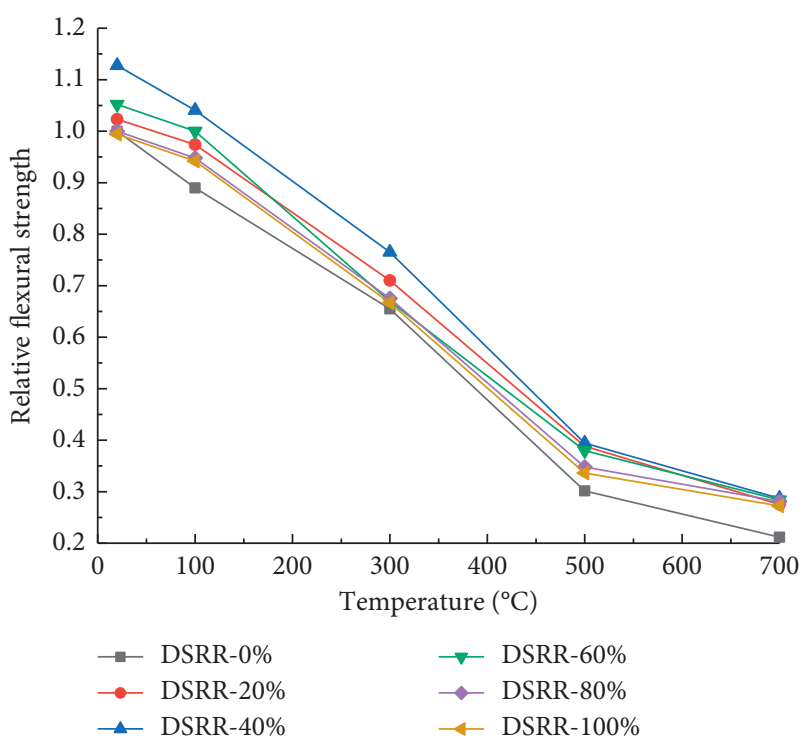

FIGURE 15: Relation between relative flexural strength and temperature.

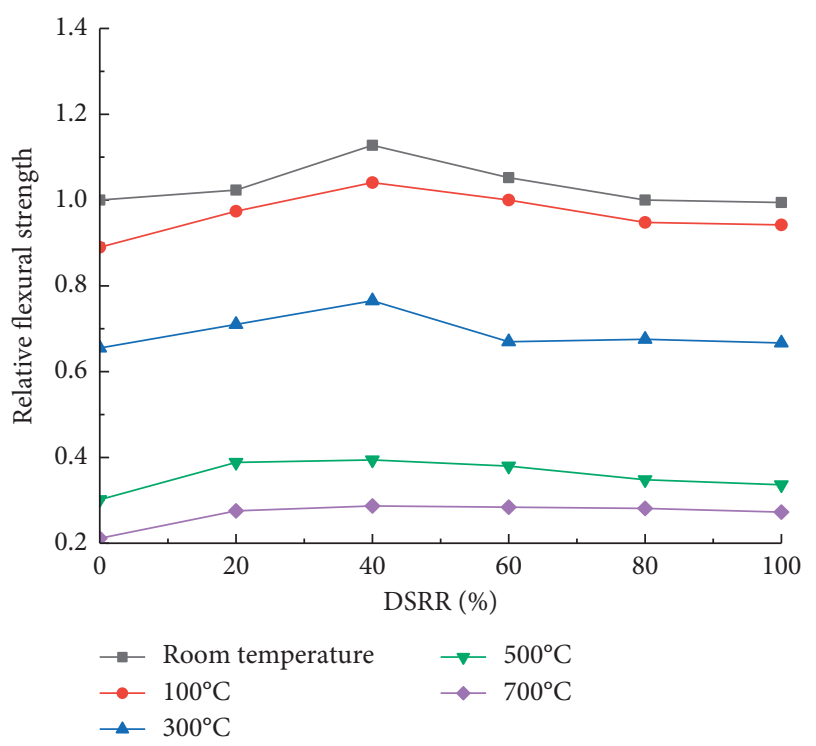

FIGURE 16: Relation between relative flexural strength and DSRR.

$$
\begin{aligned}
\frac{V_{c}(s, T)}{V_{c}}= & 1.02423-0.01134\left(\frac{T-20}{700}\right)^{2} \\
& -00.7593 s+0.06543\left(\frac{T-20}{700}\right),
\end{aligned}
$$

where $V_{c}$ represents the ultrasonic wave velocity of ordinary concrete at room temperature, $\mathrm{MPa}$.

3.5. Damage. Assuming that DSC was isotropic, following damage variable can be defined by ultrasonic wave velocity $[41,42]$.

$$
D=1-\frac{V_{c}^{2}(s, T)}{V_{c}^{2}},
$$

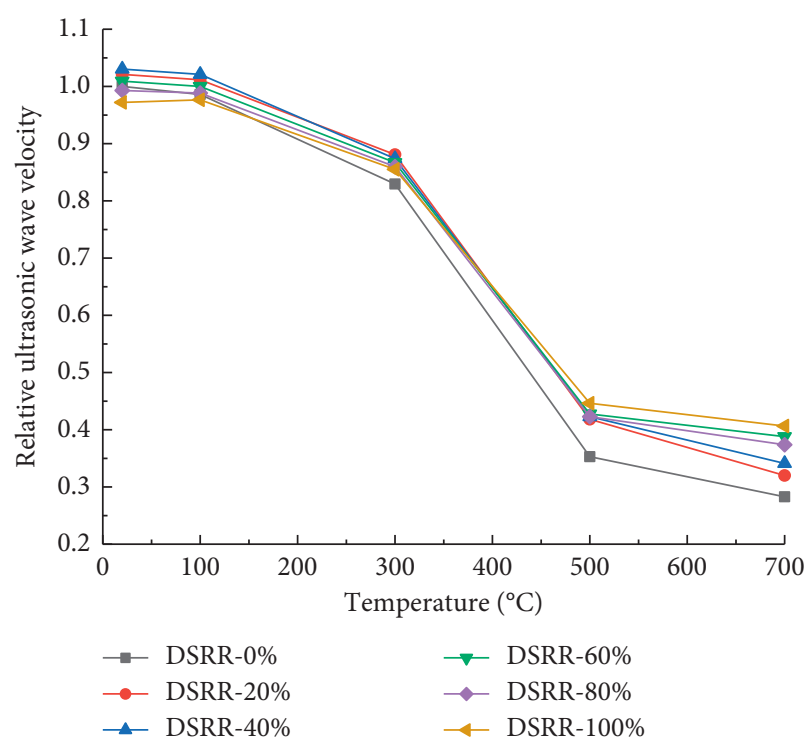

Figure 17: Relation between relative ultrasonic wave velocity and temperature.

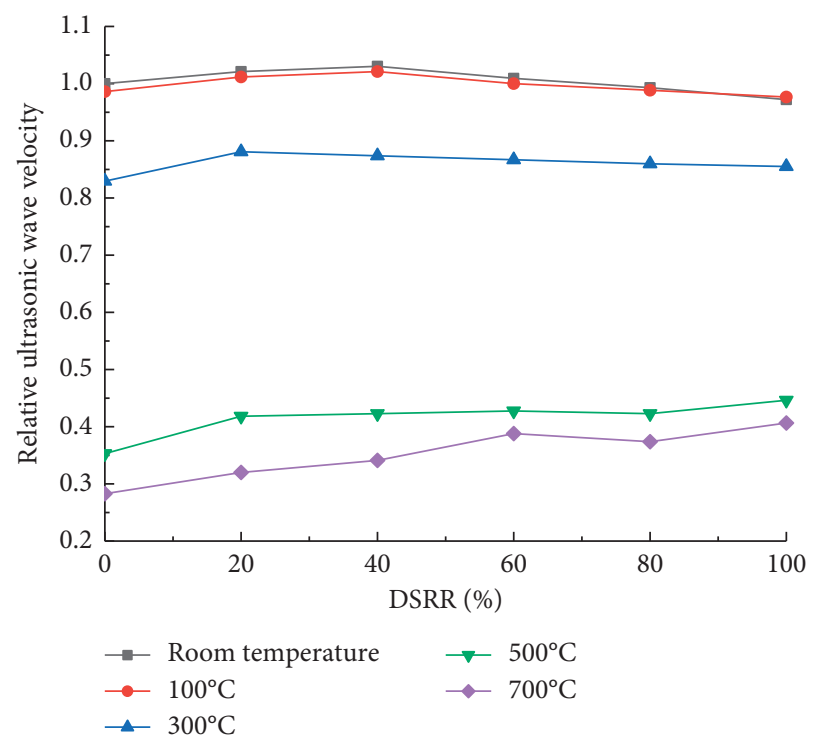

FIGURE 18: Relation between relative ultrasonic wave velocity and DSRR.

where $D$ represents the damage; $V_{c}(s, T)$ and $V_{c}$ represent the ultrasonic wave velocity of DSC before and after elevated temperature, $\mathrm{km} / \mathrm{s}$.

As shown in Figure 19, the damage of DSC increased gradually with increasing temperature. So, DSC with high DSRR can be resistant to elevated temperature.

3.6. Neutralization Depth. Typical pictures of the neutralization test of DSRR-60\% after elevated temperatures are shown in Figure 20. Compared with room temperature, the neutralized color of DSC became lighter, which indicated that carbonization caused a large increase of 


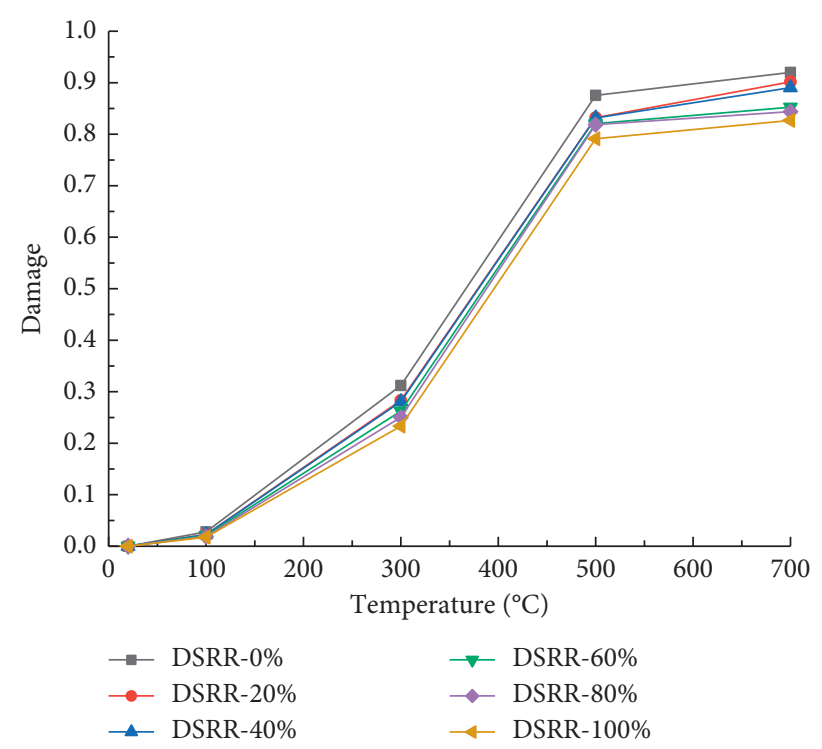

Figure 19: Relation between damage and temperature.

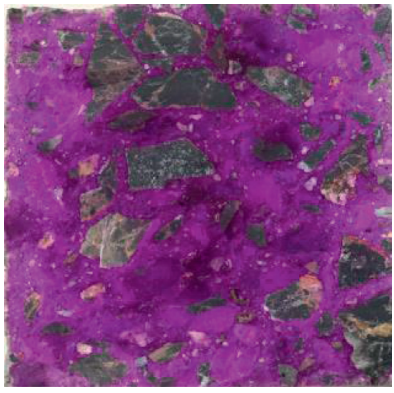

(a)

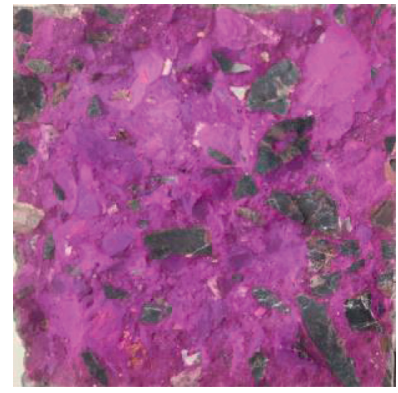

(b)

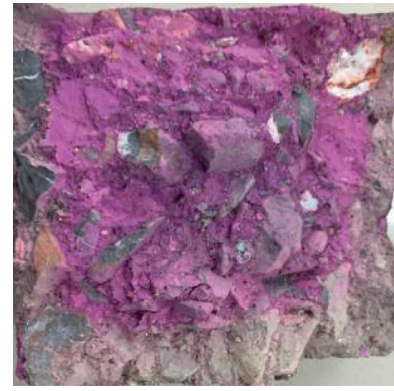

(c)

Figure 20: Neutralization test pictures of DSRR-60\% after elevated temperature. (a) Room temperature. (b) $300^{\circ} \mathrm{C}$. (c) $700^{\circ} \mathrm{C}$.

$\mathrm{CaCO}_{3}$ content. After $700^{\circ} \mathrm{C}$, pale pink appeared in the center of the cut section and the surrounding was soilcolored.

As shown in Figure 21, the neutralization depth of DSC changed little when the temperature was below $300^{\circ} \mathrm{C}$. When the temperature was above $300^{\circ} \mathrm{C}$, the neutralization depth increased greatly with increasing temperature. The relative neutralization depth of DSC decreased gradually with DSRR, which indicated that DSC with higher DSRR had a better temperature resistance effect (Figure 22).

\subsection{Analysis of XRD and SEM}

3.7.1. XRD Analysis. Phase content in different samples was proportional to X-ray diffraction peak intensity [33]. The change in $\mathrm{X}$-ray diffraction peak intensity of each phase can represent the change of phase content. X-ray diffraction analysis of DSRR-60\% after different temperatures is shown in Figure 23. The diffraction peak intensity of $\mathrm{CaCO}_{3}$ increased at $300^{\circ} \mathrm{C}$. At $700^{\circ} \mathrm{C}$, the diffraction peak intensity of $\mathrm{CaCO}_{3}$ decreased again. $\mathrm{CH}$ was decomposed completely, which indicated that the internal damage of DSC was serious. Simultaneously, there was no obvious relation between the phase content and DSRR because of the similar chemical composition of desert sand and medium sand.

3.7.2. SEM Analysis. As shown in Figure 24, DSC specimens had different looseness degree. At room temperature, the internal structures of DSRR-0\%, DSRR-60\%, and DSRR$100 \%$ specimen were relatively compact. After $300^{\circ} \mathrm{C}$, the internal structures of DSRR-0\% showed obvious cracks, DSRR-100\% showed slight cracks, and DSRR-60\% had no obvious cracks. After $700^{\circ} \mathrm{C}$, DSRR- $0 \%$ had large cracks, DSRR-100\% showed obvious cracks, DSRR-60\% showed slight cracks, and the compactness of which was better than that of DSRR-0\% and DSRR-100\% specimens.

3.8. Pore Structure Analysis. Pore structures of DSC with DSRR of $0 \%, 60 \%$, and $100 \%$ were analyzed. Figure 25 shows that the porosity of DSC enhanced with increasing temperature, which decreased first and then increased with increasing DSRR.

As shown in Figure 26, pore size distribution of DSRR$0 \%$, DSRR-60\%, and DSRR-100\% after different elevated 


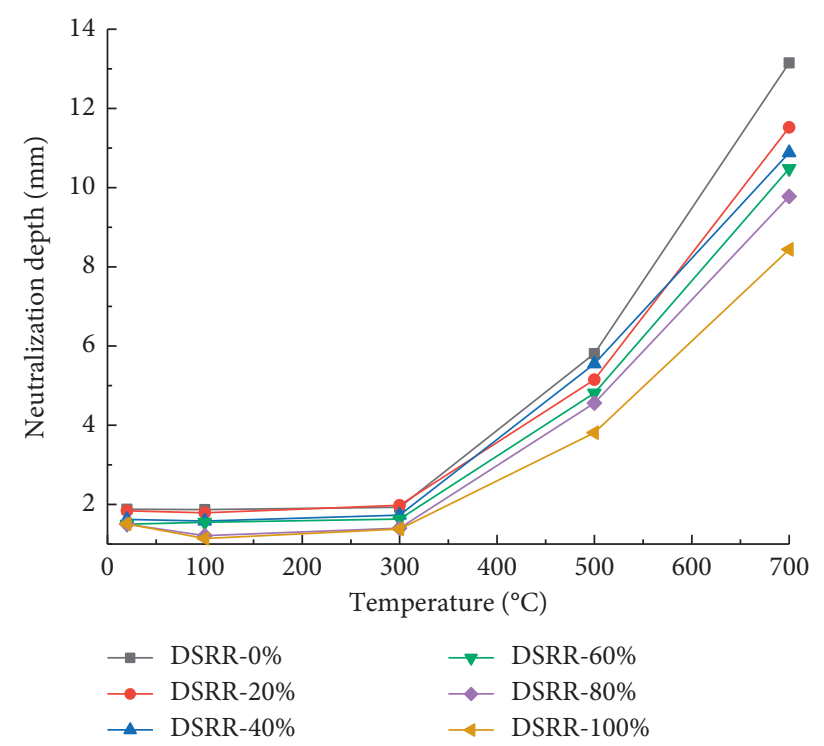

Figure 21: Relation between neutralization depth and temperature.

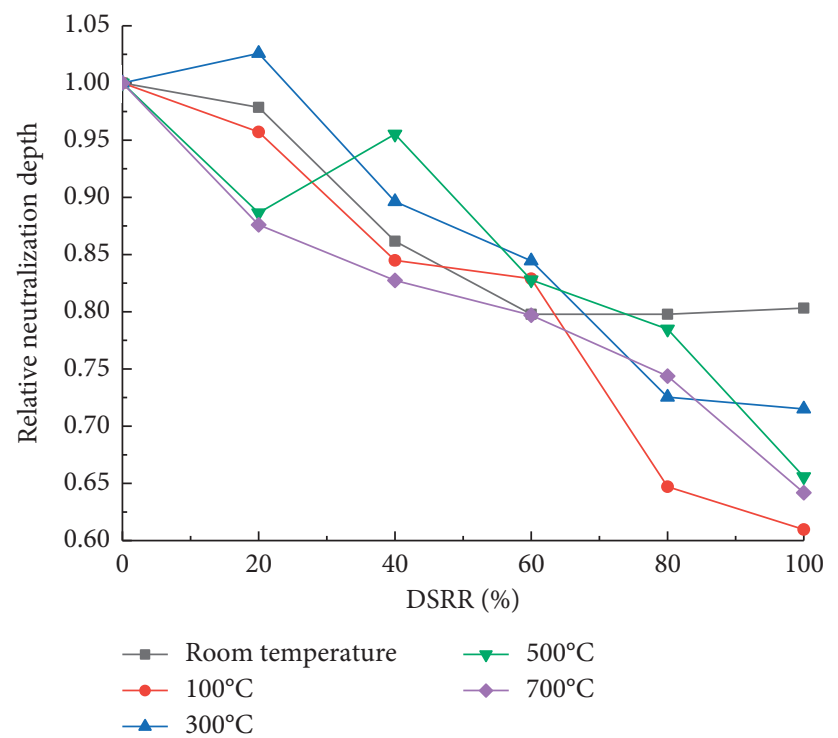

FIGURE 22: Relation between relative neutralization depth and DSRR.

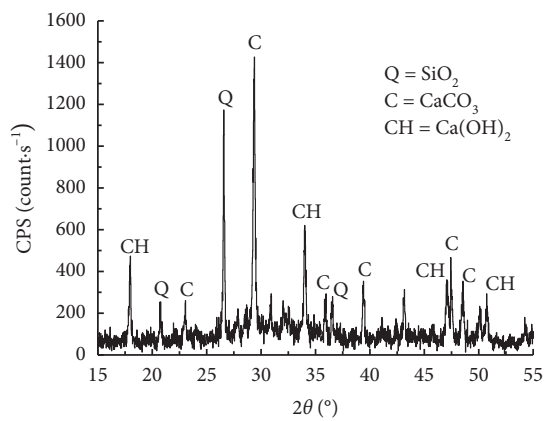

(a)

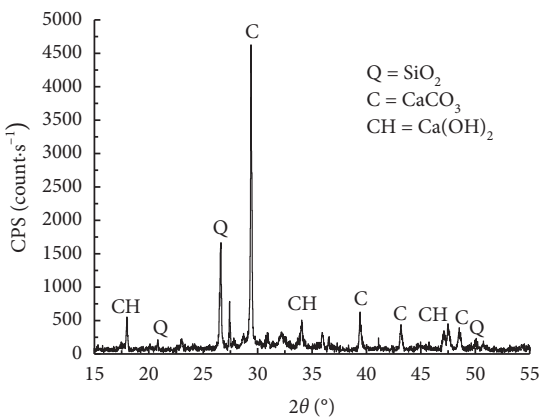

(b)

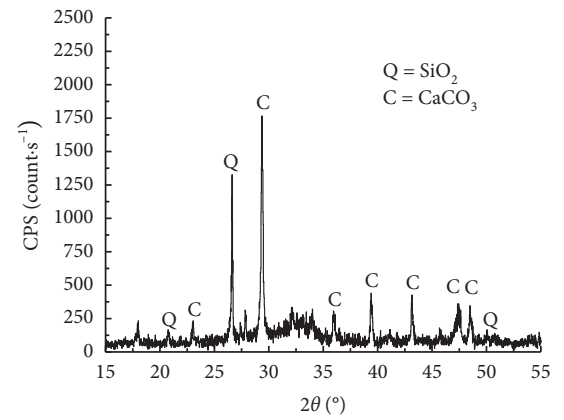

(c)

Figure 23: X-ray diffraction analysis of DSRR-60\% after different temperatures. (a) Room temperature. (b) $300^{\circ} \mathrm{C}$. (c) $700^{\circ} \mathrm{C}$. 


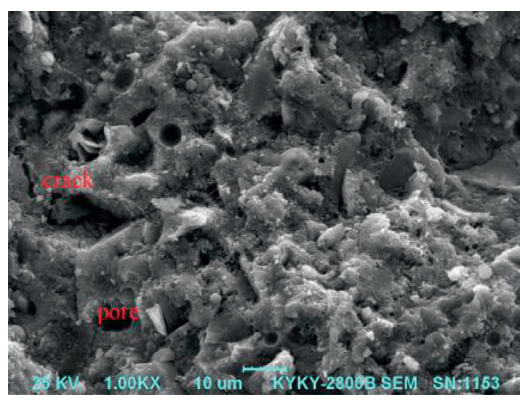

(a)

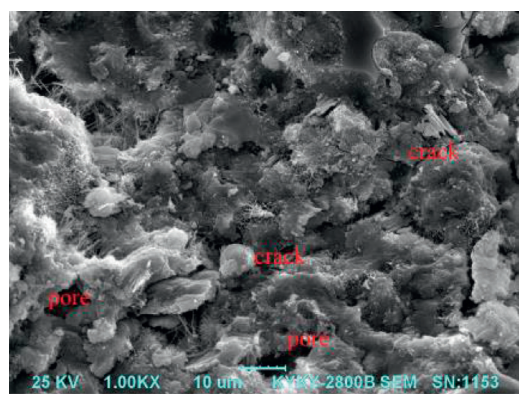

(d)

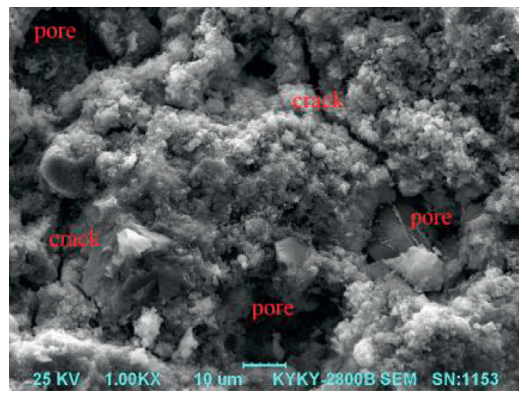

(g)

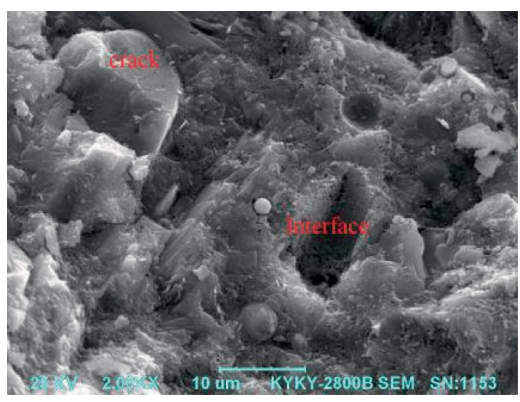

(b)

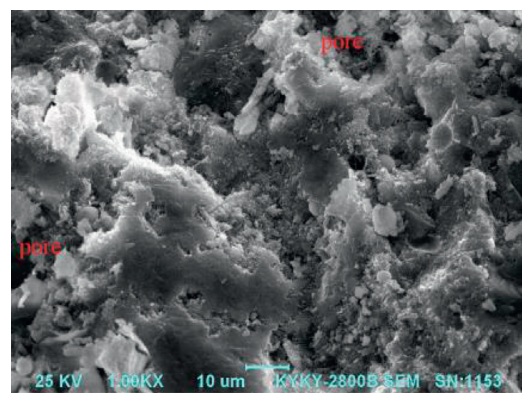

(e)

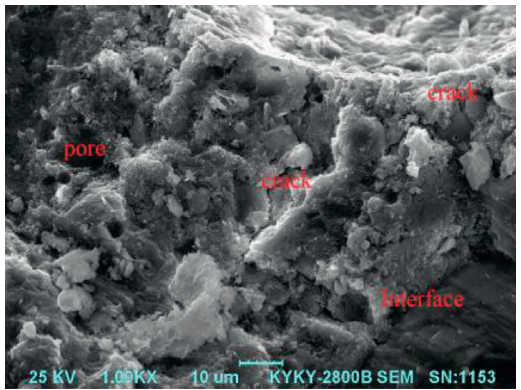

(h)

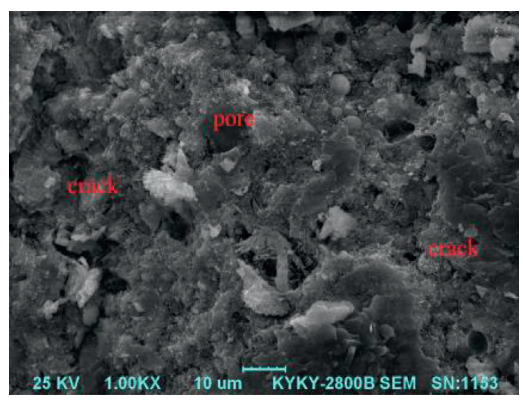

(c)

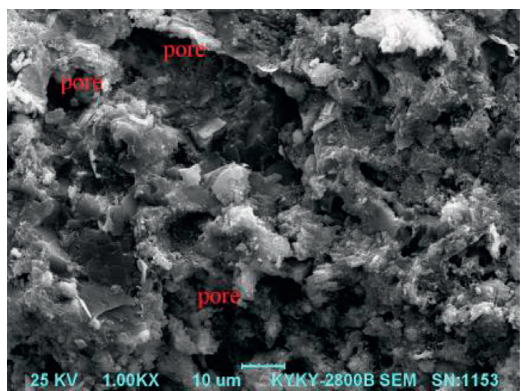

(f)

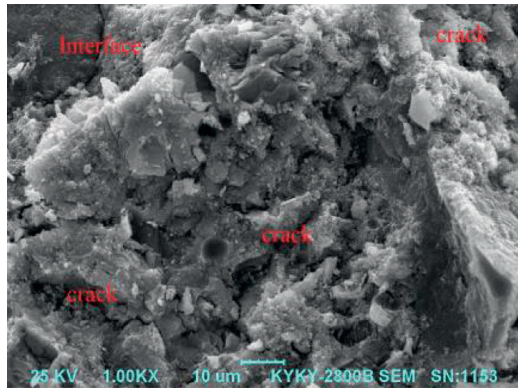

(i)

FIGURE 24: SEM of DSC after elevated temperatures. (a) Room temperature, DSRR-0\%. (b) Room temperature, DSRR-60\%. (c) Room temperature, DSRR-100\%. (d) $300^{\circ} \mathrm{C}$, DSRR-0\%. (e) $300^{\circ} \mathrm{C}$, DSRR-60\%. (f) $300^{\circ} \mathrm{C}$, DSRR- $100 \%$. (g) $700^{\circ} \mathrm{C}, \mathrm{DSRR}-0 \%$. (h) $700^{\circ} \mathrm{C}, \mathrm{DSRR}-60 \%$. (i) $700^{\circ} \mathrm{C}, \mathrm{DSRR}-100 \%$.

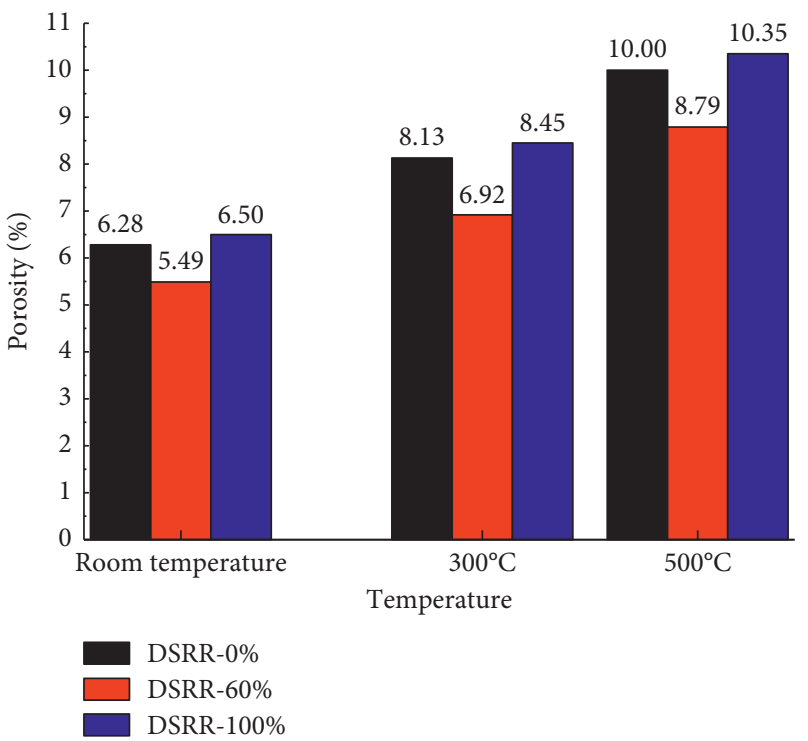

FIGURE 25: Porosity of DSC after various temperatures. 


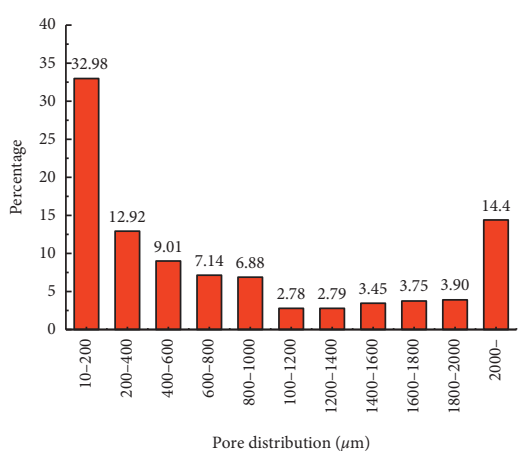

(a)

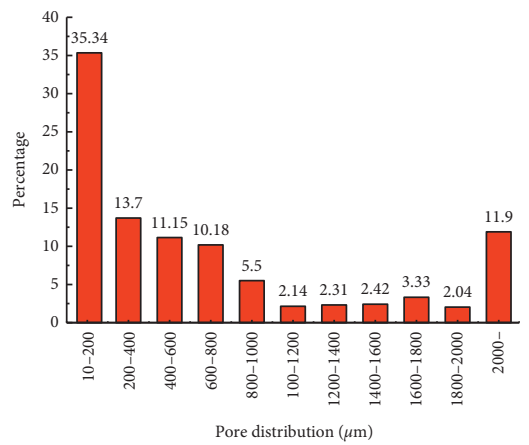

(d)

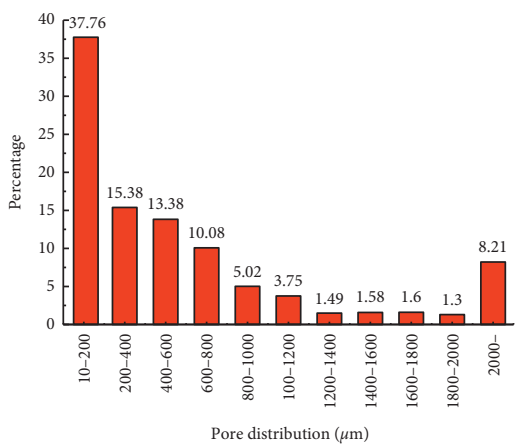

(g)

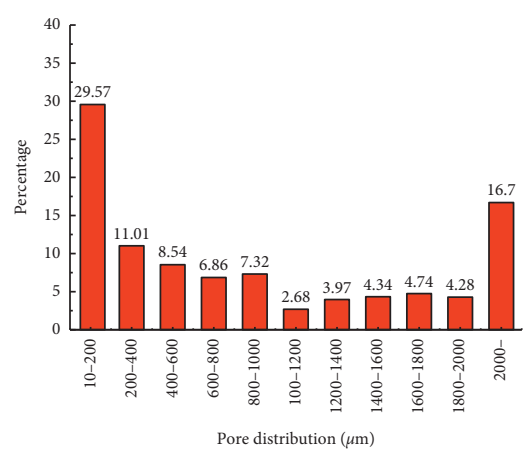

(b)

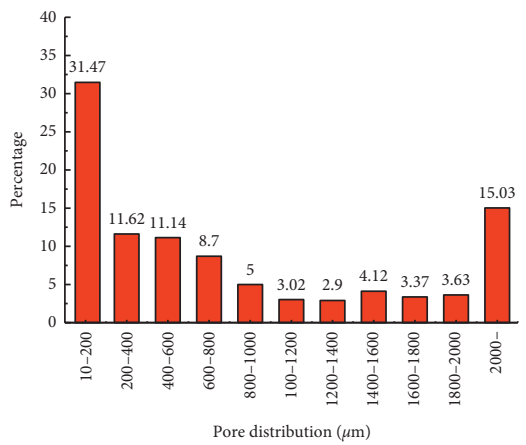

(e)

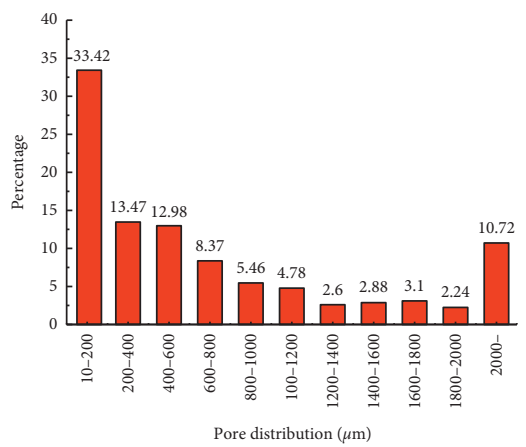

(h)

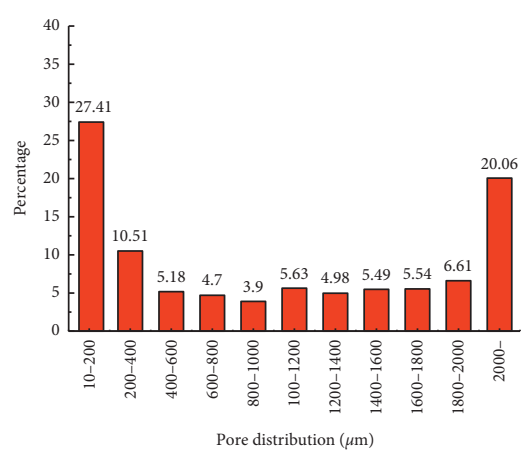

(c)

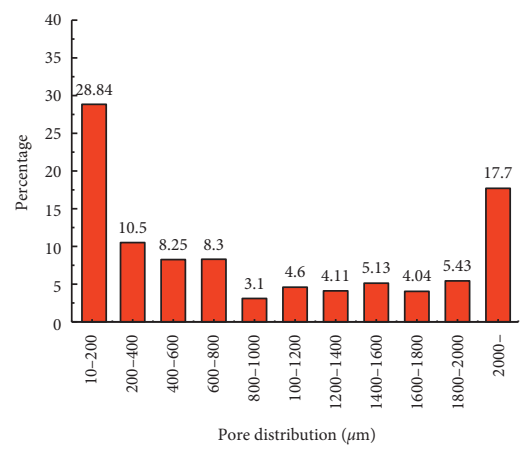

(f)

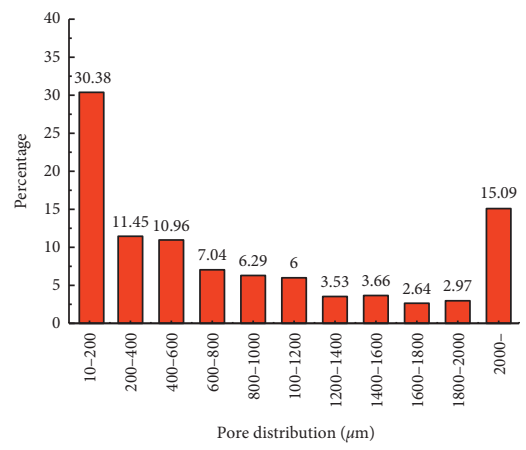

(i)

Figure 26: Pore size distribution of DSC with different DSRRs. (a) Room temperature, DSRR- $0 \%$. (b) $300^{\circ} \mathrm{C}, \mathrm{DSRR}-0 \%$. (c) $500^{\circ} \mathrm{C}, \mathrm{DSRR}-$ $0 \%$. (d) Room temperature, DSRR- $60 \%$, (e) $300^{\circ} \mathrm{C}$, DSRR-60\%. (f) $500^{\circ} \mathrm{C}$, DSRR-60\%. (g) room temperature, DSRR- $100 \%$. (h) $300^{\circ} \mathrm{C}, \mathrm{DSRR}-$ $100 \%$. (i) $500^{\circ} \mathrm{C}$, DSRR-100\%.

temperatures was similar. With increasing temperature, the porosity percentage of the pore declined as the diameter changed from $10 \mu \mathrm{m}$ to $200 \mu \mathrm{m}$. However, the porosity percentage of the pore increased with a diameter greater than $2000 \mu \mathrm{m}$. With increasing DSRR, the porosity percentage of the pore with the diameter from $10 \mu \mathrm{m}$ to $200 \mu \mathrm{m}$ increased and the porosity percentage of pore with diameter greater than $2000 \mu \mathrm{m}$ decreased.

\subsubsection{Relation between Relative Compressive Strength and} Relative Porosity. DSC relative compressive strength increased first and then decreased with increasing relative porosity after elevated temperature (Figure 27). On the basis of the regressive analysis, the relation between relative compressive strength and relative porosity was obtained by following equation. The correlation coefficient $\left(R^{2}\right)$ was 0.91.where $p(s, T)$ represents the DSC porosity after elevated temperatures $(\%) ; p_{0}$ represents the porosity of ordinary concrete at room temperature (\%).

$$
\frac{f_{c}(s, T)}{f_{c}}=-0.470\left[\frac{p(s, T)}{p_{0}}\right]^{2}+0.991 \frac{p(s, T)}{p_{0}}+0.497
$$

3.8.2. Relation between Relative Splitting Tensile Strength and Relative Porosity. DSC relative splitting tensile strength decreased with increasing relative porosity after elevated temperature (Figure 28). Based on the regressive analysis, the relation between relative splitting tensile strength and 


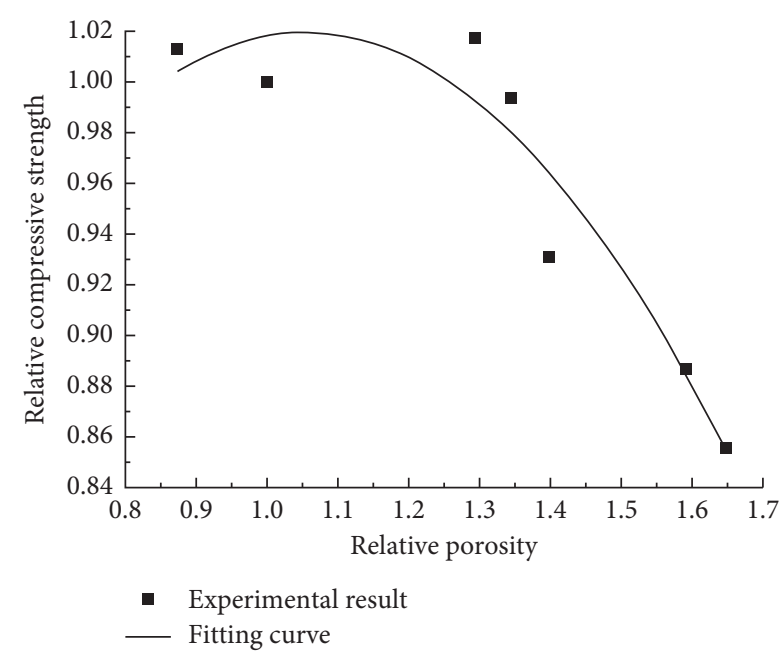

FIGURE 27: Relation between relative compressive strength and relative porosity.

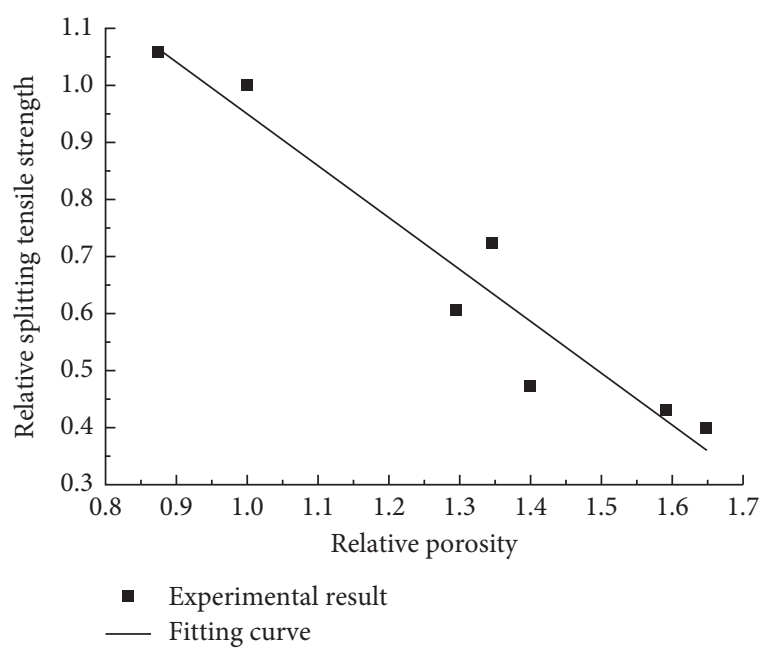

FIGURE 28: Relation between relative porosity and relative splitting tensile strength.

relative porosity of DSC was formulated. The correlation coefficient $R^{2}$ was 0.93 .

$$
\frac{f_{t}(s, T)}{f_{t}}=-0.906 \frac{p(s, T)}{p_{0}}+1.856 .
$$

3.8.3. Relation between Relative Flexural Strength and Relative Porosity. The relative flexural strength of DSC decreased with the increase of relative porosity after elevated temperature (Figure 29). Based on the regressive analysis, the relation between relative flexural strength and relative porosity of DSC after elevated temperature was established. The correlation coefficient $R^{2}$ was 0.93 .

$$
\frac{f_{f}(s, T)}{f_{f}}=-1.042 \frac{p(s, T)}{p_{0}}+1.991 .
$$

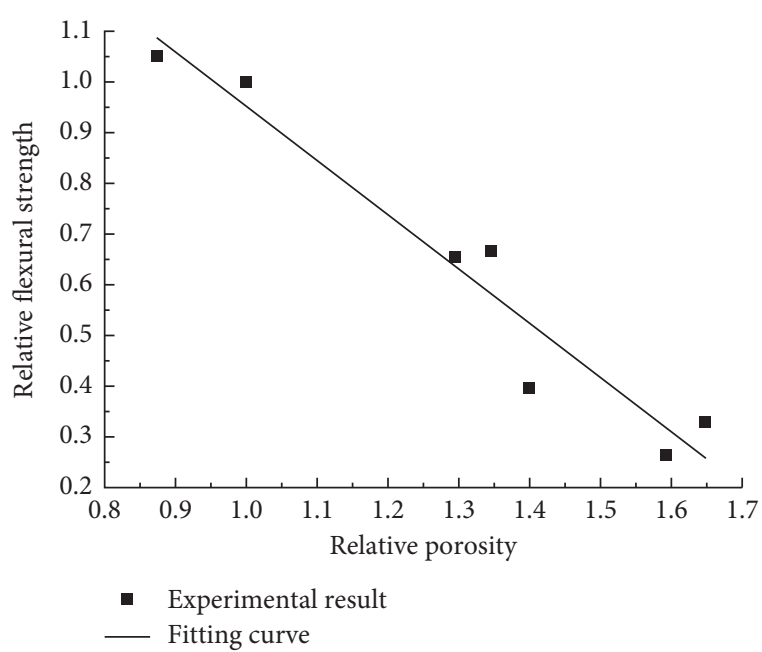

Figure 29: Relation between relative flexural strength and relative porosity.

\section{Conclusions}

The effects of elevated temperature and DSRR on DSC strength were studied by conducting mechanical properties test in this study. The microstructure was investigated by XRD and SEM. The main conclusions were as follows:

(1) With increasing temperature, DSC surface color gradually became shallower, and the cracks on the surface increased. DSC mass loss rate increased gradually with increasing temperature. The relative mass loss rate enhanced first and then decreased with increasing DSRR, and the maximum value was obtained with $20 \%$ DSRR.

(2) The effect of elevated temperature on DSC strength was greater than that of DSRR. Relative compressive strength and splitting tensile strength of DSC enhanced first and then decreased with increasing temperature. However, the relative flexural strength decreased with the temperature. Relative compressive strength, splitting tensile strength, and flexural strength of DSC enhanced first and then decreased with increasing DSRR and arrived at the maximum value when DSRR was $40 \%$.

(3) Based on the regressive analysis, the relative compressive strength was quadratic polynomial with relative porosity. Relative splitting tensile strength and flexural strength of DSC were linear with relative porosity. All correlation coefficients were above 0.9.

\section{Data Availability}

The data used to support the findings of this study are included within the article.

\section{Conflicts of Interest}

The authors declare that they have no conflicts of interest. 


\section{Acknowledgments}

The authors acknowledge the support of the Natural Science Foundation of Ningxia (2020AAC03044), Graduate Innovation Project of Ningxia University (GIP2020065), National Natural Science Foundation of China (51368048, 11162015, and 51968059), Key R\&D Projects in Ningxia (2019BBF02014), and First Class Discipline Construction in Ningxia Colleges and Universities (discipline of water conservancy engineering) (NXYLXK 2021A03).

\section{References}

[1] F. Jiang, S. H. Qi, F. Q. Liao et al., "Hydrological and sediment effects from sand mining in Poyang Lake during 2001-2010," Acta Geographica Sinica, vol. 70, no. 5, pp. 837-845, 2015.

[2] S. Dai, S. Yang, P. Li et al., "The influence of instream sand mining on the sediment discharge of mid-lower Yangtze River," Shanghai Geology, vol. 27, no. 1, pp. 17-20+28, 2007.

[3] M. Alwaeli, J. Gołaszewski, M. Niesler, J. Pizoń, and M. Gołaszewska, "Recycle option for metallurgical sludge waste as a partial replacement for natural sand in mortars containing CSA cement to save the environment and natural resources," Journal of Hazardous Materials, vol. 398, Article ID 123101, 2020.

[4] J. Che, D. Wang, H. Liu, and Y. Zhang, "Mechanical properties of desert sand-based fiber reinforced concrete (DSFRC)," Applied Sciences, vol. 9, no. 9, p. 1857, 2019.

[5] G. Zhang, J. Song, J. Yang, and X. Liu, "Performance of mortar and concrete made with a fine aggregate of desert sand," Building and Environment, vol. 41, no. 11, pp. 1478-1481, 2006.

[6] E. S. S. A. Seif, A. R. Sonbul, B. A. H. Hakami et al., "Experimental study on the utilization of dune sands as a construction material in the area between Jeddah and Mecca, Western Saudi Arabia," Bulletin of Engineering Geology and the Environment, vol. 75, no. 3, pp. 1-16, 2016.

[7] A. S. Al-Harthy, M. A. Halim, R. Taha, and K. S. Al-Jabri, "The properties of concrete made with fine dune sand," Construction and Building Materials, vol. 21, no. 8, pp. 1803-1808, 2007.

[8] W. Yan, G. Wu, and Z. Dong, "Optimization of the mix proportion for desert sand concrete based on a statistical model," Construction and Building Materials, vol. 226, pp. 469-482, 2019.

[9] F. J. Luo, L. He, Z. Pan, W. H. Duan, X. L. Zhao, and F. Collins, "Effect of very fine particles on workability and strength of concrete made with dune sand," Construction and Building Materials, vol. 47, no. 5, pp. 131-137, 2013.

[10] H. F. Liu, J. R. Ma, Y. Y. Wang et al., "Influence of desert sand on the mechanical properties of concrete subjected to impact loading," Acta Mechanica Solida Sinica, vol. 30, no. 6, pp. 583-595, 2017.

[11] H. F. Liu, Y. C. Ma, J. R. Ma et al., "Frost resistance of desert sand concrete," Advances in Civil Engineering, vol. 2021, Article ID 6620058, 17 pages, 2021.

[12] M. Zhang, H. Liu, S. Sun, X. Chen, and S. I. Doh, "Dynamic mechanical behaviors of desert sand concrete (DSC) after different temperatures," Applied Sciences, vol. 9, no. 19, p. $4151,2019$.

[13] H. F. Liu, J. R. Ma, Y. L. Chen, and D. Yang, "Mechanical properties of high strength desert sand concrete," Advanced Materials Research, vol. 1095, pp. 263-266, 2015.
[14] Q. Zhang, Q. Liu, H. F. Liu et al., "Effect of desert sand on the uniaxial compressive properties of mortar after elevated temperature," Physics and Chemistry of the Earth, vol. 121, Article ID 102962, 2020.

[15] Q. Zhang, H. F. Liu, Q. Liu et al., "Study the fire resistance of desert sand concrete (DSC) with interface phase through uniaxial compression tests and analyses," Advances in Civil Engineering, vol. 2021, Article ID 8863136, 21 pages, 2021.

[16] X. M. Li, B. Z. Ren, and X. H. Liu, "Study on fire prevention and escape safety countermeasures of urban high-rise buildings," China Safety Science Journal, vol. 19, no. 8, pp. 61-66+1, 2009, in Chinese.

[17] N. Liu, Study on the Mechanical Behavior of Desert Sand concrete after High Temperature, Ningxia University, Yinchuan, China, 2018, in Chinese.

[18] E. Annerel and L. Taerwe, "Revealing the temperature history in concrete after fire exposure by microscopic analysis," Cement and Concrete Research, vol. 39, no. 12, pp. 1239-1249, 2009.

[19] S. Ahmad, Y. S. Sallam, and M. A. Al-Hawas, "Effects of key factors on compressive and tensile strengths of concrete exposed to elevated temperatures," Arabian Journal for Science and Engineering, vol. 39, no. 6, pp. 4507-4513, 2014.

[20] A. F. Bingöl and R. Gül, "Effect of elevated temperatures and cooling regimes on normal strength concrete," Fire and Materials, vol. 33, no. 2, pp. 79-88, 2009.

[21] F. P. Jia, Y. C. Wang, Y. Y. Qu et al., "Influences of various cooling methods and standing time on residual strength of concrete after elevated temperature exposure," Journal of Building Materials, vol. 14, no. 3, pp. 400-405, 2011.

[22] T. Q. Lu, G. F. Zhao, Z. S. Lin et al., "Experimental study on mechanical properties of long standing concrete after exposure to high temperature," Journal of Building Structures, vol. 25, no. 1, pp. 63-70, 2004.

[23] T. Q. Lu, G. F. Zhao, Z. S. Lin et al., "Microscopic analysis of long standing concrete after high temperature," Journal of Building Materials, vol. 6, no. 2, pp. 135-141, 2003.

[24] X.-S. Wang, B.-S. Wu, and Q.-Y. Wang, "Online SEM investigation of microcrack characteristics of concretes at various temperatures," Cement and Concrete Research, vol. 35, no. 7, pp. 1385-1390, 2005.

[25] China Architecture and Building Press, Standard for Test Method of Mechanical Properties (GB/T 50081-2002), China Architecture and Building Press, Beijing, China, 2002, in Chinese.

[26] W. Li and Z. H. Guo, "Experimental investigation of strength and deformation of concrete at elevated temperature," Journal of Building Structures, vol. 1, pp. 8-16, 1993.

[27] Z. W. Yu, F. X. Ding, and J. P. Luo, "Experimental research on mechanical properties of different type of concrete after high temperature," Journal of Safety and Environment, vol. 5, pp. 1-6, 2005.

[28] D. F. Zhao, H. J. Gao, P. H. Jia et al., "Performance degradation of high strength concrete (HSC) after different high temperature history," Journal of Vibration and Shock, vol. 37, no. 4, pp. 240-248, 2018.

[29] B. Zhang, "Effects of moisture evaporation (weight loss) on fracture properties of high performance concrete subjected to high temperatures," Fire Safety Journal, vol. 46, no. 8, pp. 543-549, 2011.

[30] China Architecture and Building Press, Standard for Test Method of Long-Term Performance and Durability of Ordinary concrete (GB/T 50082-2009), China Architecture and Building Press, Beijing, China, 2014, in Chinese. 
[31] Astmc457/C457M-12, Standard Test Method for Microscopical Determination of Parameters of the Air-Void System in Hardened concrete, American Society for Testing Materials, West Conshohocken, PA, USA, 2012.

[32] S. Zhou, W. Sheng, Z. Wang et al., "Quick image analysis of concrete pore structure based on deep learning," Construction and Building Materials, vol. 208, pp. 144-157, 2019.

[33] H. X. Du, H. P. Wu, F. J. Wang et al., "The detection of highstrength concrete exposed to high temperatures using infrared thermal imaging technique," Materials Research Innovations, vol. 19, no. S1, pp. 162-167, 2015.

[34] B. Wu, J. Yuan, and G. Y. Wang, "Experimental study on mechanical properties of high-strength concrete after high temperature," China Civil Engineering Journal, vol. 2, pp. $8-12+34,2000$.

[35] S. K. Handoo, S. Agarwal, and S. K. Agarwal, "Physicochemical, mineralogical, and morphological characteristics of concrete exposed to elevated temperatures," Cement and Concrete Research, vol. 32, no. 7, pp. 1009-1018, 2002.

[36] H. L. Wang, Q. J. Yu, X. Y. Sun et al., "Durability and damage evaluation of concrete subjected to high temperature," Journal of Jiangsu University (Natural Science Edition), vol. 35, no. 2, pp. 238-242, 2014.

[37] G. F. Peng, J. Yang, and Y. X. Shi, "Experimental study on residual mechanical properties of ultra-high performance concrete exposed to high temperature," China Civil Engineering Journal, vol. 50, no. 4, pp. 73-79, 2017.

[38] K. F. Wang, Q. F. Xu, and T. L. Liu, "Experimental research on mechanics performance of concrete after high temperature and cooled down from high temperature," Construction Technology, vol. 8, pp. 1-3, 2005.

[39] H. F. Liu, X. L. Chen, J. L. Che et al., "Mechanical performances of concrete produced with desert sand after elevated temperature," International Journal of Concrete Structures and Materials, vol. 14, no. 1, pp. 1-15, 2020.

[40] S. Sun and H. F. Liu, "Experimental study on post-split tensile strength of desert sand area," Construction Industry, vol. 49, no. 1, pp. 140-143+169, 2019.

[41] J. Q. Gong, N. Q. Deng, and B. Shan, "Ultrasonic test and microscopic analysis of reactive powder concrete exposed to high temperature," Journal of Hunan University, vol. 45, no. 1, pp. 68-76, 2018.

[42] J. S. Zhu and Y. P. Song, "Research on fatigue damage of concrete under biaxial compressive loading using ultrasonic velocity method," Chinese Journal of Rock Mechanics and Engineering, vol. 23, no. 13, pp. 2230-2234, 2004. 